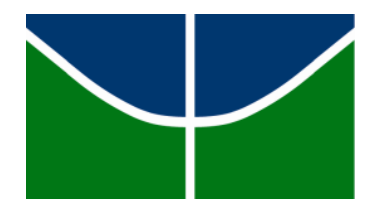

UNIVERSIDADE DE BRASÍLIA

FACULDADE DE CIÊNCIAS DA SAÚDE

PROGRAMA DE PÓS-GRADUAÇÃO EM CIÊNCIAS FARMACÊUTICAS

JULIANA CARVALHO ROCHA ALVES DA SILVA

ANÁLISE DA EXPRESSÃO DOS GENES DAS FAMÍLIAS DE METILTRANSFERASES EHMT E SUV EM PACIENTES COM LEUCEMIA LINFOIDE CRÔNICA

Brasília

2016 


\author{
UNIVERSIDADE DE BRASÍLIA \\ FACULDADE DE CIÊNCIAS DA SAÚDE \\ PROGRAMA DE PÓS-GRADUAÇÃO EM CIÊNCIAS FARMACÊUTICAS
}

JULIANA CARVALHO ROCHA ALVES DA SILVA

ANÁLISE DA EXPRESSÃO DOS GENES DAS FAMÍLIAS DE METILTRANSFERASES EHMT E SUV EM PACIENTES COM LEUCEMIA LINFOIDE CRÔNICA

Dissertação de Mestrado apresentada ao Programa de Pós-Graduação em Ciências Farmacêuticas da Faculdade de Ciências da Saúde, Universidade de Brasília, como requisito parcial à obtenção do título de Mestre em Ciências Farmacêuticas.

Orientador: Prof. Dr. Felipe Saldanha de Araújo

Co-orientadora: Profa. Dra. Doralina Rabello

Brasília

2016 
Autorizo a reprodução e divulgação total ou parcial deste trabalho, por qualquer meio convencional ou eletrônico, para fins de ensino, estudo ou pesquisa, desde que citada a fonte.

Catalogação da Publicação

(Obs.: esta catalogação é fornecida pela BCE/UnB - deve ser colocada exatamente como fornecida pelo bibliotecário)

Ficha catalográfica 


\section{ANÁLISE DA EXPRESSÃO DOS GÊNES DAS FAMÍLIAS DE METILTRANSFERASES EHMT E SUV EM PACIENTES COM LEUCEMIA LINFÓIDE CRÔNICA}

Dissertação de Mestrado apresentada ao Programa de Pós-Graduação em Ciências Farmacêuticas da Faculdade de Ciências da Saúde, Universidade de Brasília, como requisito parcial à obtenção do título de Mestre em Ciências Farmacêuticas.

Aprovada em 5 de setembro de 2016.

BANCA EXAMINADORA

Prof. Dr. Felipe Saldanha de Araújo

Dr. Jorge Vaz Pinto Neto

Prof. Dr. Marcos Rodrigo Alborghetti 
"Tudo posso naquele que me fortalece." 


\section{AGRADECIMENTO}

Primeiramente, gostaria de agradecer a Deus por me dar forças para seguir em frente em mais um desafio para a minha formação acadêmica.

Agradeço em especial ao meu orientador Prof. Felipe Saldanha que desde a iniciação científica tem me mostrado, cada dia mais, o que é ser um ser humano focado e dedicado ao crescimento científico como um todo. Com certeza, é um exemplo como profissional e pessoa que deve ser seguido por todos e que sempre me espelharei. Agradeço pelo tempo que se dedicou a me auxiliar nesse projeto, pela paciência e por se fazer tão presente em todo o meu processo de formação, desde a graduação até agora. Muito obrigada!

Agradeço muitíssimo a minha co-orientadora Doralina Rabelo por estar sempre disposta a me ajudar, pelas noites que me esperou enquanto fazia os experimentos, por toda paciência e preocupação. Obrigada por tudo de verdade!

Agradeço a todos do CancerLab pelo acolhimento e ajuda em todos os momentos.

Agradeço também à minha família, meu pai Julio, minha mãe Mara e minha irmã Mariana por todo apoio, paciência e por sempre me incentivarem em todos os momentos da minha vida. Vocês são a razão de todas as minhas conquistas.

Agradeço muito ao meu namorado Thales, por sempre me apoiar e me fazer ser uma pessoa melhor todos os dias. Obrigada por abrir mão junto comigo de diversas coisas com a finalidade de me dar suporte. Obrigada por ser meu conselheiro, ouvinte e ombro amigo sempre!

Agradeço também à empresa que trabalho VISANCO, principalmente, a minha chefe Cinara, por permitir que tivesse horários flexíveis para conseguir concluir esse sonho que era fazer meu mestrado e por todo apoio que sempre me deu. Agradecer também as minhas colegas Emiko e Natália por também sempre me apoiarem e aconselharem. 


\section{RESUMO}

ALVES-SILVA, Juliana Carvalho Rocha. Análise da expressão dos genes das famílias de metiltransferases EHMT e SUV em pacientes com leucemia linfoide crônica. Brasília, 2016. Dissertação (Mestrado em Ciências Farmacêuticas) Faculdade de Ciências da Saúde, Universidade de Brasília, Brasília, 2016.

A leucemia linfoide crônica (LLC) é uma doença linfoproliferativa que resulta no acúmulo de células B monoclonais na medula óssea, sangue periférico, linfonodos e baço. Esse câncer é mais prevalente em países ocidentais, sendo mais frequentemente diagnosticado em homens após 70 anos. Embora a etiologia da doença seja desconhecida, alguns fatores prognósticos são bem conhecidos como a expressão da proteína ZAP-70, alta contagem de células malignas (leucocitose) associado ao tempo de duplicação linfocitária e alterações cariotípicas específicas ou aquisição de cariótipo complexo (3 ou mais alterações cariotípicas). Atualmente, a fisiopatologia de diversos tipos de neoplasias tem sido relacionada a mecanismos epigenéticos. Nesse sentido, foi demonstrado que a expressão das enzimas Histona Metiltransferases (HMTs) das famílias Euchromatic Histone-Lysine N-Methyltransferase (EHMT) e Suppressor Of Variegation (SUV) podem estar relacionadas à instabilidade genômica e ao pior prognóstico de alguns tipos de câncer. Considerando essas associações, investigamos nesse trabalho a expressão dos genes membros das famílias EHMT e SUV em pacientes com LLC e associamos esses achados a marcadores de prognóstico, como: expressão da proteína ZAP-70, cariótipo e leucometria desses pacientes. Nesse trabalho, observamos que a baixa expressão do gene SUV39H1 está associada à aquisição de anormalidades citogenéticas em pacientes com LLC. A expressão elevada de SUV39H2 está associada à baixa contagem de plaquetas e a um maior número de casos com alterações cariotípicas. A baixa expressão de SUV420H1 está relacionada com maior leucometria, enquanto que a baixa expressão de SUV420H2 está associada à expressão elevada de ZAP-70. EHMT1 se mostrou com expressão elevada nas amostras de LLC, enquanto que EHMT2, embora não tenha apresentado expressão diferencial entre LLC e pacientes saudáveis, está associado à aquisição de cariótipo complexo nessa doença. Nossos dados evidenciam que as famílias de metiltransferases SUV e EHMT estão associadas à aquisição de indicadores de mau prognóstico na LLC, como contagem de plaquetas, maior número de células malignas, expressão de ZAP-70 e aquisição de cariótipo complexo. Esses dados contribuem para a área de epigenética e câncer, podendo servir de base para o desenvolvimento de novas abordagens terapêuticas que visem controlar processos epigenéticos na LLC.

Palavras-chave: Leucemia Linfoide Crônica, SUV, EHMT, ZAP-70, metiltransferases. 


\begin{abstract}
ALVES-SILVA, Juliana Carvalho Rocha. Analysis of gene expression of the families of methyltransferases EHMT and SUV in patients with chronic lymphocytic leukemia. Brasília, 2016. Dissertação (Mestrado em Ciências Farmacêuticas) Faculdade de Ciências da Saúde, Universidade de Brasília, Brasília, 2016.

Chronic lymphocytic leukemia (CLL) is a lymphoproliferative disease that results in accumulation of monoclonal B cells in bone marrow, peripheral blood, lymph nodes and spleen. This cancer is more prevalent in Western countries, being more often diagnosed in men after age 70. Although the etiology of the CLL is unknown, some prognostic factors are well known as the expression of ZAP-70, the high quantity of malignant cells (leukocytosis) associated with lymphocyte duplicating time and karyotype changes or acquisition of complex karyotype (three or more karyotype alterations). Currently, the pathophysiology of various types of cancers has been linked to epigenetic mechanisms. In this line, it was shown that the expression of the enzymes histone methyl Transferases (HMTs) of Euchromatic Histone-Lysine N-Methyltransferase (EHMT) and Suppressor Of Variegation (SUV) families may be related to genomic instability and to bad prognosis markers of some cancers. Considering these associations, we investigated in this study the expression of EHMT and SUV members in CLL samples. Furthermore, we investigated the association of gene expression analysis and prognosis markers, like: ZAP-70 expression, karyotype and white blood cell count of these patients. In this study, we found that low expression of SUV39H1 gene is associated with the presence of cytogenetic abnormalities in patients with CLL. The high expression of SUV39H2 is associated with low platelet count and with the presence of cytogenetic abnormalities. Low SUV4-20H1 expression is related to the accumulation of leukocytes, while the low SUV4-20H2 expression influences the expression of ZAP-70. EHMT1 was high expressed in LLC, while EHMT2 was associated with the presence of complex karyotype in this disease. Our data clearly show that the methyltransferases SUV and EHMT influence generally in CLL, being associated with the presence of bad prognosis markers in this disease, including platelet count, accumulation of malignant cells, expression of ZAP-70 and abnormal karyotype. These results may provide the basis for the development of new therapeutic strategies to prevent CLL progression.
\end{abstract}

Keywords: Chronic Lymphoid Leukemia, SUV, EHMT, ZAP-70, methyltransferases. 


\section{LISTA DE FIGURAS}

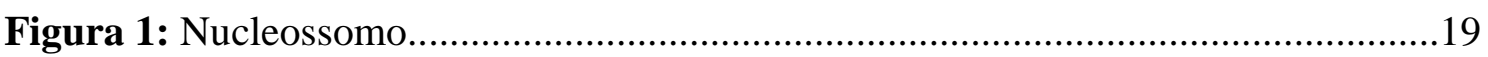

Figura 2: Mecanismos epigenéticos e RNA não-codificante........................................20

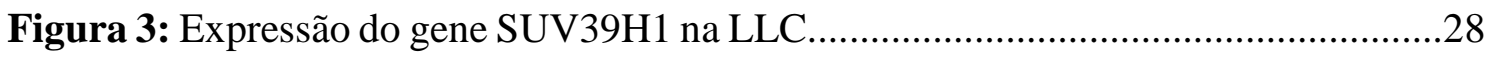

Figura 4: Correlação do gene SUV39H1 e contagem de leucócitos, plaquetas e expressão da proteína ZAP-70.

Figura 5: Análise de contingência correlacionando o gene SUV39H1 e o cariótipo de pacientes com LLC...... .30

Figura 6: Expressão do gene SUV39H2 na LLC.

Figura 7: Correlação do gene SUV39H2 e contagem de leucócitos, plaquetas e expressão da proteína ZAP-70. .32

Figura 8: Análise de contingência correlacionando o gene SUV39H2 e o cariótipo de pacientes com LLC. .33

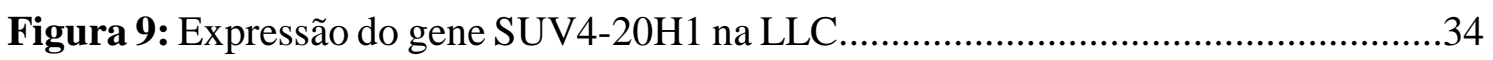

Figura 10: Correlação do gene SUV4-20H1 e contagem de leucócitos, plaquetas e expressão da proteína ZAP-70. .34

Figura 11: Análise de contingência correlacionando o gene SUV4-20H1 e o cariótipo de pacientes com LLC .35

Figura 12: Expressão do gene SUV4-20H2 na LLC... 36

Figura 13: Correlação do gene SUV4-20H2 e contagem de leucócitos, plaquetas e expressão da proteína ZAP-70. .37

Figura 14: Análise de contingência correlacionando o gene SUV4-20H2 e o cariótipo de pacientes com LLC .37

Figura 15: Expressão do gene EHMT1 na LLC. 38 
Figura 16: Correlação do gene EHMT1 e contagem de leucócitos, plaquetas e expressão da proteína ZAP-70.

Figura 17: Análise de contingência correlacionando o gene EHMT1 e o cariótipo de pacientes com LLC .39

Figura 18: Expressão do gene EHMT2 na LLC. 40

Figura 19: Correlação do gene EHMT2 e contagem de leucócitos, plaquetas e expressão da proteína ZAP-70.

Figura 20: Análise de contingência correlacionando o gene EHMT2 e o cariótipo de pacientes com LLC .42

Figura 21: Correlação entre a expressão genica do gene SUV4-20H2 e os outros genes da família SUV

Figura 22: Correlação entre a expressão gênica do gene EHMT1 e do gene EHMT2 


\section{LISTA DE TABELAS}

Tabela 1: Sistema de estadiamento de Binet. .16

Tabela 2: Relação entre cariótipo mutado ou não-mutado e mau prognóstico .18

Tabela 3: Quadro resumo das correlações estudadas .23

Tabela 4: Características clínicas e laboratoriais dos pacientes com LLC. .27 


\section{LISTA DE ABREVIATURAS E SIGLAS}

FISH: Hibridização fluorescente in situ

P53: Gene supressor de Tumor

TCR: Receptores de Células T

BCR: Receptores de Células B

INCA: Instituto Nacional de Câncer José Alencar Gomes da Silva

Ig: Imunoglobulina

LLC: Leucemia Linfoide Crônica

LPL: Lipoproteína Lipase

CD19: Em inglês: cluster of differentiation 19

CD38: Em inglês: cluster of differentiation 38

ADAM39: Em inglês: disintegrin and metallopeptidase domain 39

$\mathrm{Pb}$ : Pares de bases

PCR: Reação em cadeia polimerase

ZAP-70: Preteína cinase 70 kda associada a cadeia Zeta

Del: deleção

G9a: Methyltransferase methylates lysine 9

cDNA: DNA complementar

IgVH: região variável da cadeia pesa na imunoglobulina

SUV39H1: Suppressor Of Variegation 3-9 Homolog 1

SUV39H2: Suppressor Of Variegation 3-9 Homolog 2

SUV4-20H1: Suppressor Of Variegation 4-0 Homolog 1

SUV4-20H2: Suppressor Of Variegation 4-0 Homolog 2

EHMT1: Euchromatic Histone-Lysine N-Methyltransferase 1

EHMT2: Euchromatic Histone-Lysine N-Methyltransferase 2

HMT: Histona Metil Transferases 
HMTase: Enzima Histona metiltransferase

H3K9: Enzima Histona lisina 9 metiltransferase

H3K27: Enzima Histona lisina 27 metiltransferase

H4K20: Enzima Histona lisina 20 metiltransferase

HDAC: Enzima de Histona Deacetilação 


\section{SUMÁRIO}

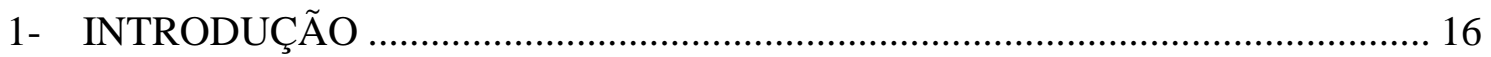

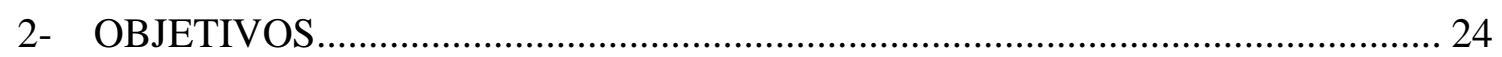

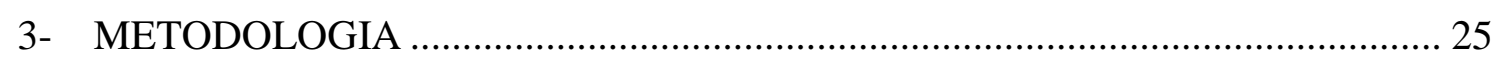

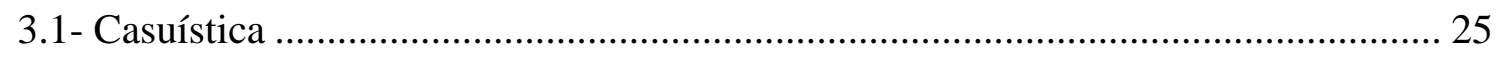

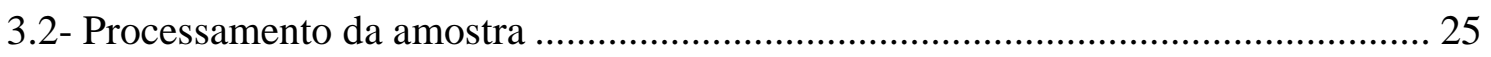

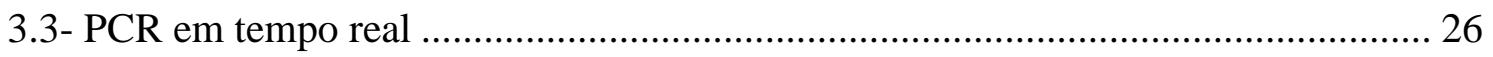

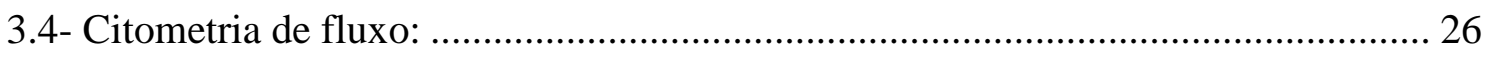

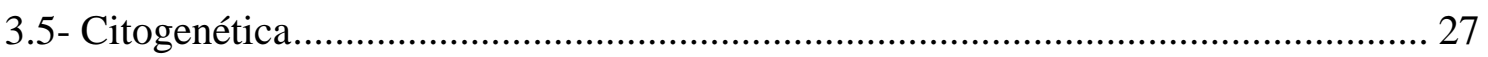

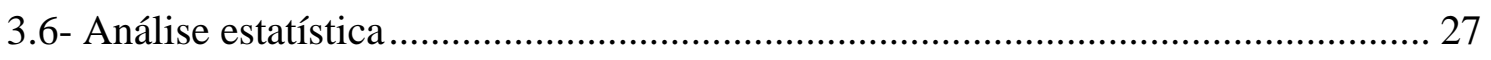

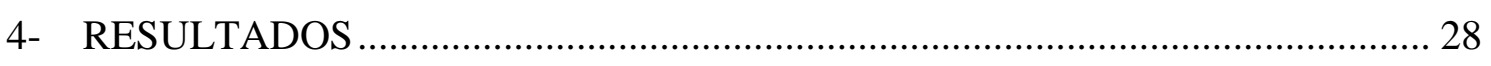

4.1 Expressão de SUV39H1 na leucemia linfoide crônica.............................................. 28

4.2 A expressão do gene SUV39H1 não se associa a leucometria, contagem de plaquetas e expressão da proteína ZAP-70 em pacientes com LLC............................................... 29

4.3 A baixa expressão do gene SUV39H1 está relacionada com a presença de cariótipos anormais na LLC. ................................................................................................ 30

4.4 Expressão de SUV39H2 na leucemia linfoide crônica............................................... 31

4.5 A expressão do gene SUV39H2 não influencia na expressão da proteína ZAP-70 e contagem de leucócitos em pacientes com LLC, mas está associada a contagem diferencial de plaquetas. .................................................................................... 32

4.6 A expressão elevada de SUV39H2 está associada a presença de cariótipo anormal na LLC . . . . . . 33

4.7 Expressão de SUV4-20H1 na leucemia linfoide crônica. ......................................... 34

4.8 A expressão elevada de SUV4-20H1 está relacionada com uma baixa contagem total de leucócitos e não influencia na contagem de plaquetas e na expressão da proteína ZAP-

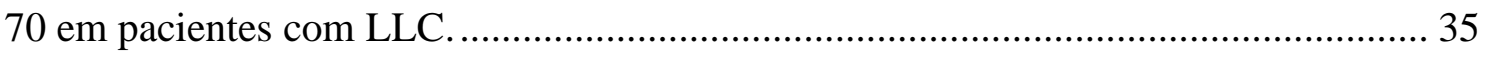

4.9 Nenhuma relação entre a expressão do gene SUV4-20H1 e alteração cariotípica foi

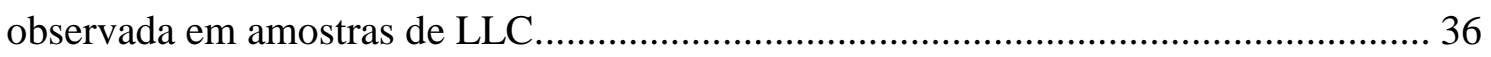

4.10 Expressão de SUV4-20H2 na leucemia linfoide crônica. ........................................ 36

4.11 A baixa expressão de SUV4-20H2 está relacionada com aumento na expressão de ZAP-70 e não influencia na contagem de plaquetas e leucometria de pacientes com LLC.

4.12 O gene SUV4-20H2 não influencia na alteração citogenética de pacientes com LLC 38 
4.13 O gene EHMT1 possui expressão mais elevada na LLC que em células B normais.

4.14 A expressão do gene EHMT1 não se associa a leucometria, contagem de plaquetas e expressão da proteína ZAP-70 em pacientes com LLC.

4.15 Nenhuma relação entre a expressão do gene EHMT1 e os cariótipos dos pacientes

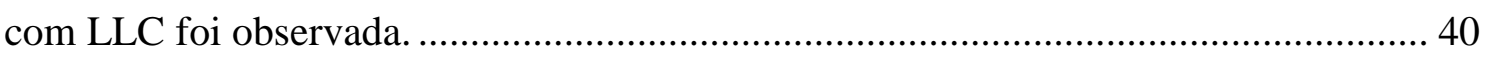

4.16 Expressão de EHMT2 na leucemia linfoide crônica. ........................................... 41

4.17 A expressão do gene EHMT2 não se associa a leucometria e expressão da proteína ZAP-70 em pacientes com LLC. Contudo, foi observada relação com a contagem de plaquetas. 41

4.18 O EHMT2 influencia o cariótipo dos pacientes com LLC .................................... 42

4.19 A expressão de SUV4-20H2 apresentou correlação com a expressão dos outros

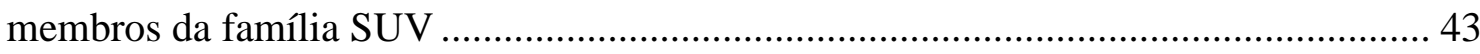

4.20 A expressão de EHMT1 apresentou correlação com a expressão de EHMT2 ....... 44

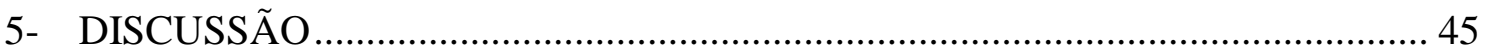

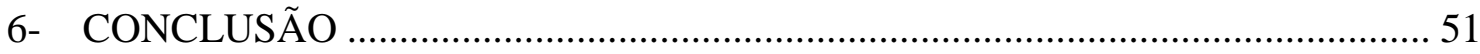

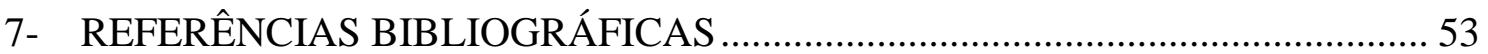




\section{1- INTRODUÇÃO}

A leucemia linfoide crônica (LLC) é uma doença que se caracteriza pelo acúmulo de linfócitos B monoclonais CD5 + no sangue periférico, medula óssea e órgãos linfóides secundários (baço e gânglios linfáticos). Essa doença é normalmente caracterizada por leucometria elevada, com aumento na contagem de linfócitos no sangue periférico superior a $5 \times 10^{9} \mathrm{~L}^{1}$, sendo em uma parte dos casos de LLC, o principal sintoma apresentado é a linfoadenomegalia (GHIA, P., et al., 2007).

A LLC é a leucemia mais comum em adultos no mundo ocidental, representando cerca de $25-30 \%$ de todas as leucemias. Essa doença acomete mais homens que mulheres, com uma proporção de 1,5-2: 1 e a taxa de incidência é de cerca de 2-6 novos casos a cada 100 mil indivíduos por ano nos Estados Unidos (EUA). Essa taxa aumenta com a idade, chegando a 12,8 / 100.000 / ano. Recentemente, um aumento na incidência entre os indivíduos mais jovens foi relatado, sendo um terço de novos casos é diagnosticado antes dos 55 anos de idade (GHIA, P., et al., 2007). A prevalência de LLC, que é o número total/proporção de casos existentes numa determinada população e num determinado momento temporal, é de aproximadamnte 30-50: 100.000 (0,03-0,05\%), com base na incidência estimada e no tempo médio de sobrevivência ao longo da doença (GHIA, P., et al., 2007). Os pacientes com essa doença são classificados segundo alguns sistemas. Os sistemas de classificação mais conhecidos são os sistemas de Rai e Binet, sendo este último o mais utilizado (BINET L., et al., 2006, RAI, K.R.; et al., 1975).

No sistema de Binet (Tabela 1) os pacientes que não apresentam anemia, trombocitopenia e possuem menos de três áreas com acúmulo de células linfóides são classificados como Binet A. Estes correspondem a 55\% dos pacientes e possuem sobrevida maior que 10 anos. Os pacientes do grupo B não possuem anemia, trombocitopenia e apresentam três ou mais aréas com acúmulo de células linfóides. Cerca 
de $30 \%$ dos pacientes possuem essa classificação, tendo sobrevida média de 7 anos. O grupo C é o que possui menor prevalência, sendo que os pacientes apresentam anemia e/ou trombocitopenia e possuem sobrevida media de 2 anos (BINET L., et al., 2006).

Tabela 1: Apresentação da forma de organização do estadiamento de Binet, as características e o período de sobrevida dos pacientes.

\begin{tabular}{|c|c|}
\hline BINET & CARACTERÍSTICAS CLÍNICAS DO ESTAGIO BINET \\
\hline A & $\begin{array}{c}\mathrm{Hb} \geq 10 \mathrm{~g} / \mathrm{dL}, \text { plaquetas } \geq 100.000 \mathrm{~mm} 3 \text {, duas } \\
\text { ou menos regiões linfonadais acometidas }\end{array}$ \\
\hline B & $\begin{array}{c}\mathrm{Hb} \geq 10 \mathrm{~g} / \mathrm{dL}, \text { plaquetas } \geq 100.000 \mathrm{~mm} 3 \text {, três } \\
\text { ou mais regiões linfonadais acometidas }\end{array}$ \\
\hline $\mathrm{C}$ & $\begin{array}{c}\mathrm{Hb}<10 \mathrm{~g} / \mathrm{dL} \text { e/ou plaquetas }<100.000 \mathrm{~mm} 3 \text {, anemia e/ou } \\
\text { plaquetopenia }\end{array}$ \\
\hline
\end{tabular}

Hb: Hemoglobina. Adaptado BINET,2006

O número elevado de leucócitos representa um marcador prognóstico clássico na LLC (COCISIU, G., et al, 2011), entretanto, um dos principais marcadores prognósticos dessa doença é a cadeia zeta associada à proteína quinase (ZAP-70) - um membro da família Syk quinase - envolvida na sinalização de receptores de células T (TCR) e nos processos de ativação das células $\mathrm{T}$, apoptose e migração celular. Foi demostrado que ZAP-70, que se pensava estar ausente em células B normais, está envolvido na sinalização do receptor de célula $\mathrm{B}$ (BCR) e se associa ao mau prognóstico na leucemia linfoide crônica (LLC) (ZENT C. S., et al., 2008).

Outro marcador prognóstico é o status mutacional a região variável da cadeia pesada de imunoglobulina ( $\operatorname{IgVH}$ ), sendo que o prognóstico do paciente com LLC é pior quando essa cadeia não está mutada. A avaliação da expressão do marcador CD38, por envolver citometria de fluxo, é de execução mais simples e está relacionado com o status mutacional da IgVH. 
Existem também alguns potenciais marcadores que estão se mostrando úteis para análise de prognostico na LLC. Esses possíveis marcadores são o perfil de expressão de lipoproteína lipase LPL, LPL/ADAM29 e Vimentina. Outras análises também realizadas para essa doença são padrão histomorfológico da infiltração na medula óssea e o tempo de duplicação linfocitária (VASCONCELOS Y., 2005).

Outro fator que pode ser analisado para verificar o comportamento dessa enfermidade é a presença de alterações cariotípicas. De modo geral, alterações cromossômicas indicam um pior prognóstico em comparação com o cariótipo normal. Döhner et al. demostraram que entre 325 pacientes com LLC, em $82 \%$ foi detectada aberração cromossômica na interfase por hibridização de fluorescência in situ (FISH). Dentre essas altereações pode-se citar como mais frequentes: deleção no cromossomo 13q (55\%), trissomia 12 (18\%), e uma deleção no cromossomo 11q (16\%). Uma deleção no cromossomo $17 \mathrm{p}$, que afeta a proteína TP53, foi vista com menos frequência (7\%). A presença da deleção de $17 \mathrm{p}$ ou 11q está associada a pior prognóstico e predomina em estágios avançados de LLC e em pacientes com genes IgVH não mutados, enquanto que a deleção $13 q$ ou a presença de um cariótipo normal podem ser associadas com um bom prognóstico, fases iniciais da doença e genes mutados IgVH (Tabela 2). Existe controvérsia sobre se trissomia 12 é associada a um status não mutado de IGVH e mau prognóstico. Pacientes acometidos por LLC com cariótipos mutados e não-mutados diferem claramente em termos de prognóstico. Alterações cariotípicas, normalmente, encontram-se relacionadas a um mau prognóstico (DIGHIERO, G. \& HAMBLIN, T.J., 2008).

Indivíduos com anormalidades cromossômicas individuais tendem a apresentar uma expectativa de vida mais longa do que pacientes com múltiplas alterações (NASCIMENTO, M., et al, 2006). De fato, a aquisição de cariótipo complexo (três ou 
mais anormalidades citogenéticas) se apresenta como um indicador de má evolução da LLC (DOHNER, H.; et al., 2000; MAYR, C.; et al., 2006).

Tabela 2: Relação entre cariótipo mutado ou não-muado e mau prognóstico.

\begin{tabular}{|c|c|c|c|c|c|}
\hline & \multicolumn{5}{|c|}{ CARIÓTIPO } \\
\hline & & $13 q$ & Trissomia & $11 \mathrm{q}$ & $17 q$ \\
\hline & Normal & Deleção & 12 & Deleção & Deleção \\
\hline Total de pacientes $(\%)$ & 18 & 55 & 16 & 18 & 7 \\
\hline \multicolumn{6}{|l|}{ Estágio Binet $(\%)^{*}$} \\
\hline$A^{*}$ & 53 & 72 & 51 & 25 & 23 \\
\hline $\mathrm{B}^{*}$ & 30 & 20 & 34 & 50 & 41 \\
\hline \multirow{2}{*}{\multicolumn{6}{|c|}{$\begin{array}{c}\mathrm{C}^{*} \\
\text { Sobrevida média (meses) }\end{array}$}} \\
\hline & & & & & \\
\hline para Binet A & 120 & 132 & 120 & 84 & 30 \\
\hline
\end{tabular}

Tem se demonstrado que muitas alterações genéticas detectadas nos cânceres decorrem de alterações epigenéticas. A epigenética estuda as mudanças herdadas na expressão dos genes, observadas na genética, mas que não alteram as sequências de bases nucleotídicas da molécula de DNA (EGGER G., et al., 2004). O estudo de doenças humanas tem se concentrado em mecanismos genéticos, mas a ruptura do equilíbrio das redes epigenéticas pode causar diversas patologias graves, como o câncer, síndromes envolvendo instabilidades cromossômicas e retardo mental (EGGER G., et al., 2004).

Foi demostrado que as enzimas metiltransferasses podem contribuir para a instabilidade genônica levando ao desenvolvimento e progressão de cânceres. Essas enzimas não alteram a estrutura genômica, porém a mudança no padrão de metilação, promovido por elas, pode levar a ativação de proto-oncogenes e o silenciamento de genes 
supressores de tumor, propiciando o desenvolvimento de diversos tipos de cânceres (WARD L.S., 2002).

Existem vários estudos que associam alterações epigenéticas e o câncer, principalmente no que tange padrões anormais de metilação. A metilação, conforme, descrito anteriormente, é realizada por enzimas metiltransferases, sendo que as HMTs agem transferindo grupos metil às histonas, tornando a cromatina inativa (MULLER \& PRADO, 2008).

À unidade fundamental da cromatina, é dado o nome de nucleossomo, que pode ser observado na Figura 1. Essa unidade é formada por DNA e quatro pares de histonas que podem ser classificadas como (H2A, H2B, H3 e H4) (REECE J., et al., 2002).

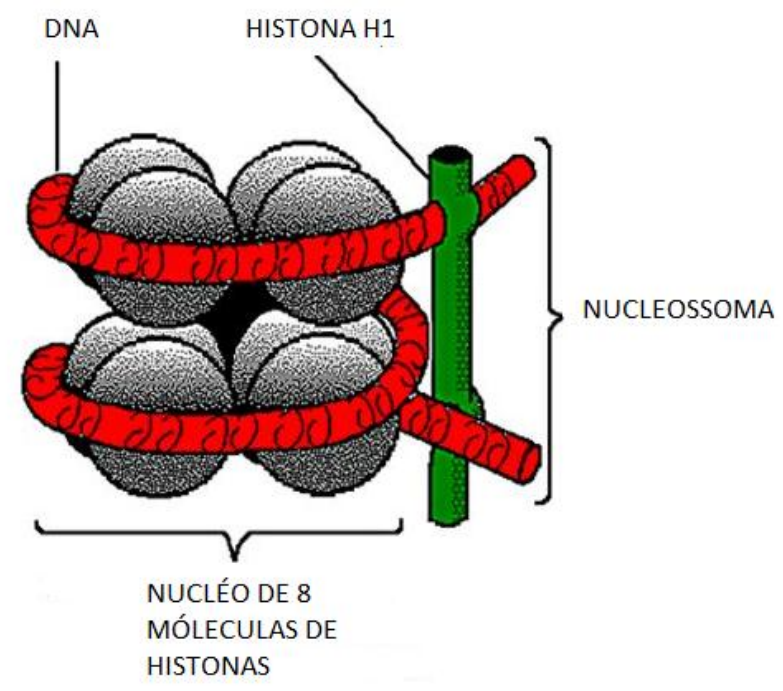

Figura 1: Modelo de estrutura do nucleossomo. O DNA em dupla hélice enrola-se em torno do octâmero formado por duas moléculas de cada uma das histonas H2A, H2B, H3 e H4, constituindo o centro do nucleossomo. A histona H1 liga-se externamente ao centro do nucleossomo e ao DNA de ligação, constituindo o nucleossomo (REECE J., et al., 2002).

As histonas, que compõem o nucleossomo, podem sofrer alterações póstranscricionais, como metilação, ubiquitinação e acetilação, o que afetará o padrão de expressão gênica (Figura 2). Além disso, o próprio DNA pode sofrer metilação e, como 
exemplo, esses três mecanismos (metilação, ubiquitinação e acetilação) são conhecidos como fatores epigenéticos (PASCHON, V., et al., 2014).

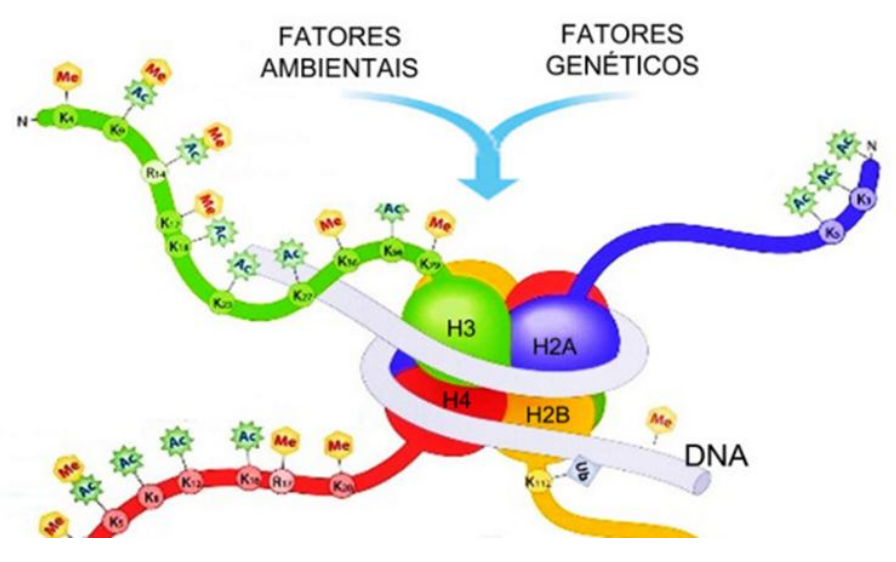

Figura 2: Mecanismos epigenéticos nos nucleossomos. O DNA é enrolado em torno de quatro histonas cujas caudas estão sujeitas a modificações pós-transcricionais, incluindo acetilação e metilação, o que dá origem ao "código-histona" que afeta a expressão gênica. O DNA também pode sofrer metilação e afetar a expressão gênica (PASCHON, V., et al., 2014).

Esses padrões anormais de metilação, tanto nas histonas como no DNA, muitas vezes podem estar relacionados com o câncer. Principalmente quando há hipermetilação das ilhas $\mathrm{CpG}$, que se encontram na região promotora de genes que atuam na supressão tumoral, e a hipometilação global (MULLER \& PRADO, 2008).

Com o intuito de desenvolver novos alvos terapêuticos para o tratamento de câncer, algumas estruturas epigenéticas estão sendo estudadas. Por exemplo, nosso grupo recentemente demonstrou que alta expressão de alguns membros de metiltransferases como a EZH2 e SMYD2 estão diretamente relacionadas ao mau prognóstico dos pacientes portadores de LLC e leucemia llinfoide aguda, respectivamente (RABELLO D.D., et al., 2015 ;SAKAMOTO L.H., et al., 2014). É interessante, pois demonstramos 
também que a família SMYD, representada por SMYD2 e SMYD3, também exerce influência na progressão da LLC (OLIVEIRA-SANTOS et al 2016).

SUV e EHMT constituem famílias de metiltransferases pouco estudadas até o momento. A família de metiltransferases SUV é composta pelas enzimas SUV39H1, SUV39H2, SUV4-20h1 e SUV4-20h2. Essas enzimas são responsáveis pela trimetilação da histona H3K9 (SUV39H1, SUV39H2,) e pela di- e trimetilação de histonas H4 lisina 20 (H4K20me2 e H4K20me3) nos telômeros (SUV4-20h1 e SUV4-20h2). (BENETTI R., et al., 2007). Já a metiltransferase EHMT é responsável pela mono e di-metilação da histona H3 na lisina 9 (H3K9), a alta expressão desse gene foi verificada em cânceres de fígado (KONDO, Y., et al., 2007).

Apesar do papel das metiltransferases no câncer não estar completamente elucidado, foi demonstrado que quando as metiltransferases EHMT e SUV39H1 não são expressas no câncer de próstata, ocorre inibição da propagação de células malignas por meio do não silenciamento de genes supressores de tumor e, no caso das células que não expressam EHMT, há uma desordem nos centrômeros resultando em instabilidade cromossômica, o que leva a inibição do crescimento e quiescência celular. Além disso, EHMT é necessária para a expressão da telomerase transcriptase reversa (hTERT) e, com sua inibição, há uma perda na manutenção dos telômeros, promovendo, assim, a morte celular. Já as células cancerígenas que não expressaram SUV39H1 apresentam telômeros menores devido a um alongamento anormal. Esses achados indicam de que as HMTs podem ser consideradas como potenciais alvos terapêuticos para o tratamento do câncer (KONDO, Y., et al., 2008).

Em face ao exposto, pretendemos avaliar se as metiltransferases das famílias EHMT e SUV estão relacionadas com marcadores conhecidos de mau prognóstico em 
pacientes com LLC. Os resultados obtidos nesse estudo poderão servir de base para a busca de novos alvos terapêuticos baseados em mecanismos epigenéticos. 


\section{2- OBJETIVOS}

\section{Geral:}

- Avaliar a expressão gênica das famílias de metiltransferase SUV e EHMT na LLC e investigar a associação dessas enzimas com marcadores prognósticos desse câncer.

\section{Específicos:}

- Avaliar a expressão da proteína ZAP-70 em pacientes com LLC;

- Determinar o cariótipo dos pacientes;

- Determinar a expressão dos genes da família SUV em pacientes com LLC;

- Determinar a expressão dos genes da família EHMT em pacientes com LLC;

- Investigar a correlações da expressão dos genes das famílias SUV e EHMT com os dados laboratoriais (leucometria e contagem de plaquetas); expressão da proteína ZAP-70 e citogenética da população em estudo;

Tabela 3: Quadro resumo das correlações estudadas.

\begin{tabular}{ccc} 
Metiltransferases & Genes & Marcadores Estudados \\
\hline \multirow{2}{*}{ SUV } & SUV39H1 & Expressão dos genes na LLC \\
& SUV39H2 & Expressão da proteína ZAP-70 \\
& SUV4-20H1 & Cariótipo dos pacientes \\
& SUV4-20H2 & Leucometria \\
\multirow{2}{*}{ EHMT } & EHMT1 & Contagem de Plaquetas \\
& EHMT2 & \\
\hline
\end{tabular}




\section{3- METODOLOGIA}

3.1- Casuística: as amostras utilizadas nesse estudo foram provenientes de 59 pacientes com LLC atendidos no serviço de hematologia da Faculdade de Medicina de Ribeirão Preto-USP. O diagnóstico de LLC desses pacientes foi estabelecido com base no número de leucócitos, na morfologia celular e na identificação de marcadores imunofenotípicos por citogenética (MATUTES, E, et al. 1994). Para esse estudo, foram utilizadas 10 amostras de células B como controle. Essas amostras foram obtidas a partir do sangue periférico coletado de indivíduos saudáveis, com idade média pareada. No estudo foram admitidas amostras de indivíduos entre 50 a 84 anos. O termo de consentimento livre esclarecido (TCLE) foi obtido para todos os pacientes e voluntários saudáveis e a execução do estudo foi aprovada pelo comitê de ética local.

3.2- Processamento da amostra: As células usadas como controle nesse estudo foram isoladas por meio de coluna imunomagnética (Miltenyi Biotec, BergischGladbach, Germany), seguindo as instruções do fabricante. Em suma, as células mononucleares do sangue periférico (PBMC) foram incubadas com o anticorpo monoclonal CD19 conjugado com microbeads (Miltenyi Biotec) e, posteriormente, a suspensão celular foi dispensada em uma coluna LS (MACS Separation Columns; Miltenyi Biotec) previamente acoplada em um imã (SuperMACS). As células tiveram na sua superfície a ligação de beads e ficaram retidas no campo magnético. Posteriormente a coluna foi retirada do campo magnético e as células tiveram avaliação de pureza, por citometria de fluxo (FacsCalibur, BD). Foram utilizadas nesse estudo as amostras com marcação de CD19 superior a 90\%.

Com relação às amostras de LLC, após coleta, o sangue total foi centrifugado a $2000 \mathrm{rpm}$ por 10 minutos. Posteriormente, $2 \mathrm{ml}$ de plasma foram recolhidos e congelados a $-80^{\circ} \mathrm{C}$ para incorporar estudos futuros do grupo. $\mathrm{O}$ material restante da amostra 
(hemácias, células mononucleares e restante do plasma) foi submetido à centrifugação com gradiente Ficoll-hypaque por 2000 rpm, 25 minutos. Após a centrifugação, formouse uma fase com células mononucleares que foi recolhida e submetida a extração de RNA pelo método de TRIZOL-LS (Invitrogen Inc.). Realizada a extração de RNA, as amostras foram quantificadas por espectrofotometria através do aparelho NanoVue (General Eletrics). Após quantificação do RNA, $1 \mu \mathrm{g}$ desse material foi submetido a transcrição reversa por uso do High Capacity cDNA Archive Kit (Applied BioSystems), conforme instruções do fabricante.

3.3- PCR em tempo real: A análise quantitativa da expressão dos genes SUV39H1, SUV39H2, SUV4-20H1, SUV4-20H2 e EHMT1 e EHMT2 foi realizada em amostras de células B controle e em amostras de LLC pela metodologia TaqMan (Applied Biosystems). Os primers e sondas foram adquiridos pelo sistema AssayOnDemand. O gene calibrador utilizado foi a B-actina, obtido pelo sistema PDAR (Applied Biosystems), cuja eficiência de amplificação é a mesma dos genes alvos, o que possibilita a análise dos dados pela metodologia de DDCt (LIVAK \& SCHMITTGEN, 2001; PFAFFL, 2001). O fold encontrado nas análises se refere a expressão dos genes das metiltransferases estudadas nas amostras de LLC em relação às amostras controle.

3.4- Citometria de fluxo: $O$ sangue periférico $(5 \mathrm{~mL})$ de todos os pacientes com LLC foi coletado em EDTA. As células mononucleares foram isoladas em gradiente de densidade Ficoll Hypaque (Sigma-Aldrich, St Louis, MO, USA), após centrifugação. A concentração final foi ajustada para $10^{6}$ células por tubo. O painel inicial de citometria de fluxo, utilizada para diagnóstico dos casos recrutados, consistiu no uso dos seguintes anticorpos: CD20 FITC, CD79b PE, CD19 PE-Cy5, CD5 APC (ii), anti- $\lambda$ FITC, anti- $\kappa$ PE. Todos os anticorpos monoclonais foram obtidos da Becton Dickinson (San Jose, CA, USA), exceto os anticorpos anti- $\lambda$ e anti- $\kappa$ (Dako, Carpinteria, CA, USA). Ademais, foi 
analisada a presença do marcador prognóstico ZAP-70 (San Jose, CA, USA), no citometro de fluxo FACSCalibur (Becton Dickinson).

3.5- Citogenética: A análise do cariótipo foi realizada por bandeamento $G$ no Laboratório de Hematologia da Faculdade de Medicina de Ribeirão Preto. Em suma, foram utilizadas $1 \times 10^{7} \mathrm{PBMC}$, sendo que a metáfase foi induzida em meio RPMI-1640 (Invitrogen, Gaithersburg, MD) com 20\% de SBF na presença do oligonucleotídeo imunoestimulatório DSP30 (TIBMolBiol, Berlin, Germany) e interleucina 2 (IL-2). Após 72 horas em cultura, foi adicionado colcemid (Sigma, Munich, Germany) antes da preparação dos cromossomos.

3.6- Análise estatística: Foi utilizado o software Prism 5 (GraphPad Software Inc., San Diego, CA, USA) para as análises estatísticas. O nível de significância adotado foi de 5\% (CI 95\%). Para as comparações envolvendo dois e três grupos, utilizamos o teste Mann-Whitney e ANOVA, respectivamente. Para o estudo de análise de contingência utilizamos o teste exato de Fisher. As barras de linha presentes na análise referem-se ao desvio padrão da amostra. 


\section{4- RESULTADOS}

Analisando as características clínicas e laboratoriais dos 59 pacientes com LLC agrupados no estudo encontramos $66 \%$ dos casos foram classificados como Binet A, $22 \%$ como Binet B e 12\% como Binet C. Nessa amostragem, 25\% dos casos apresentaram cariótipo normal e 75\% mostraram algum tipo de alteração citogenética (Tabela 4).

Tabela 4: Características clínicas e laboratoriais dos pacientes com LLC

\begin{tabular}{c|c|c}
\multicolumn{1}{c}{ PARÂMETROS } & CARACTERÍSTICAS & PACIENTES \\
\hline \multirow{2}{*}{ GÊNERO } & HOMENS & $35(59,3 \%)$ \\
\cline { 2 - 3 } & MULHERES & $24(40,7 \%)$ \\
\cline { 2 - 3 } IDADE & IDADE MÉDIA & 63 ANOS \\
\hline \multirow{2}{*}{$\begin{array}{c}\text { ESTADIAMENTO } \\
\text { BINET }\end{array}$} & BINEUIÇÃO & 32 A 98 ANOS \\
\cline { 2 - 3 } & BINET B & $39(66 \%)$ \\
\cline { 2 - 3 } & BINET C & $73(22 \%)$ \\
\cline { 2 - 3 } & DELEÇÃO 13q & $5(8,3 \%)$ \\
\cline { 2 - 3 } ANÁLISE & DELEÇÃO 17q & $4(6,7 \%)$ \\
\cline { 2 - 3 } CITOGENÉTICA* & TRISSOMIA 12 & $16(26,7 \%)$ \\
\cline { 2 - 3 } & OUTROS & $15(25 \%)$ \\
\cline { 2 - 3 } & NORMAL & $39(67,2 \%)$ \\
\cline { 2 - 3 } $\begin{array}{c}\text { EXPRESSÃO } \\
\text { DE ZAP-70** }\end{array}$ & $>20 \%$ & $19(32,8 \%)$ \\
\cline { 2 - 3 }
\end{tabular}

* Uma amostra apresentou trissomia do 12 e deleção 13q sendo alocada nos dois grupos.

** Um dado foi perdido.

\subsection{Expressão de SUV39H1 na leucemia linfoide crônica.}

Não encontramos diferença significativa no nível de expressão do gene SUV39H1 entre pacientes com LLC e as amostras controle $(\mathrm{p}=0.4)$ (Figura 3). Entretanto, é possível identificar que o grupo de pacientes com LLC possui uma expressão heterogênea do gene SUV39H1. Esse perfil de expressão nos levou a estratificar a expressão desse gene em 
amostras com elevada e baixa expressão de SUV39H1, baseado na mediana da expressão. Com isso, passamos a avaliar se a alta ou baixa expressão desse gene estaria relacionada com os demais dados clínico-laboratoriais determinados nesse estudo.

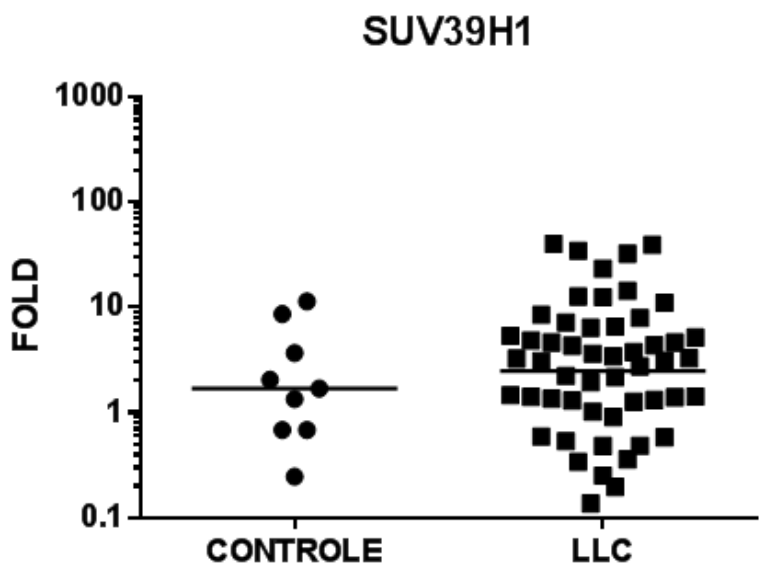

Figura 3: Expressão do gene SUV39H1 na LLC.A expressão do gene foi realizada em amostras de LLC e em células B de pacientes saudáveis, pela técnica de PCR. A análise estatística foi realizada pelo Teste Mann Whitney. 1 amostra do controle e 7 de LLC não expressaram SUV39H1.

4.2 A expressão do gene SUV39H1 não se associa a leucometria, contagem de plaquetas e expressão da proteína ZAP-70 em pacientes com LLC.

O nível de expressão do gene SUV39H1 não se correlacionou com o número de leucócitos $(\mathrm{p}=0.1)$ e o número de plaquetas $(\mathrm{p}=0.4)$ de pacientes com LLC. Também não encontramos diferença estatisticamente significante com relação à expressão da proteína ZAP-70 em pacientes que possuem expressão diferencial de SUV39H1 ( $p=0.07)$. Entretanto, foi observado que os pacientes que apresentaram baixa expressão desse gene possuem expressão de ZAP-70 24,5\% superior aos pacientes que possuem expressão elevada de SUV39H1 (32,8 x 40,8) (FIGURA 4). 
A

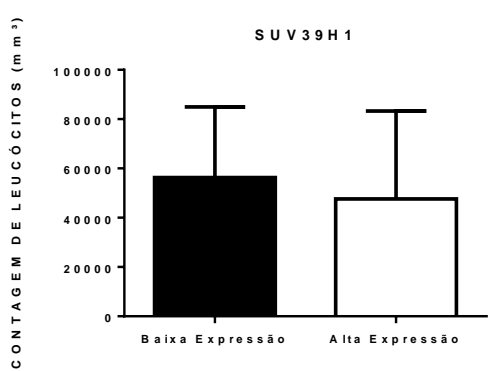

B

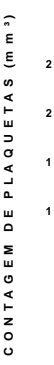

B

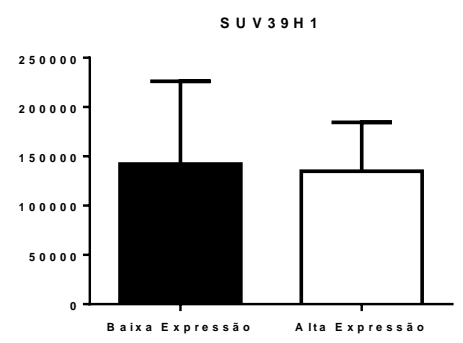

C

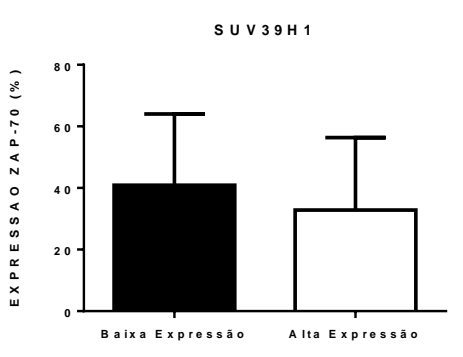

Figura 4: Associação entre SUV39H1 e achados laboratoriais. A: Associação entre expressão do gene SUV39H1 e a contagem de leucócitos; B: contagem de plaquetas e C: expressão de ZAP-70 em pacientes com LLC. Teste Mann Whitney.

\subsection{A baixa expressão do gene SUV39H1 está relacionada com a presença de cariótipos anormais na LLC.}

Por análise de contingência, identificamos que a baixa expressão de SUV39H1 está relacionada com maior frequência de cariótipos anormais ( $\mathrm{p}=0.01)$ na LLC. Considerando esse achado, estratificamos as amostras em casos que possuem cariótipo normal e aqueles que possuíam qualquer alteração cromossômica. A partir disso, avaliamos se o nível de expressão do gene SUV39H1 exercia influência no resultado citogenético. Os indivíduos que apresentam cariótipo anormal apresentaram expressão diminuída do gene da SUV39H1, em relação aos casos que apresentaram expressão elevada desse gene ( $\mathrm{p}=0.04)$. Em seguida, avaliamos se a expressão do gene SUV39H1 exercia correlação com a presença de cariótipo complexo em pacientes com LLC. Para isso, os pacientes com LLC foram divididos em três grupos: cariótipo normal; com apenas 1 ou 2 alterações cromossomais e; perfil gênico com 3 ou mais alterações cromossômicas (cariótipo complexo). A baixa expressão do gene SUV39H1 mostrou estar associada à presença de cariótipo complexo na LLC (p=0.003) (Figura 5). 
A

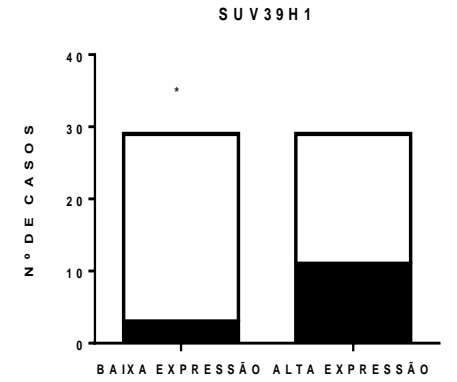

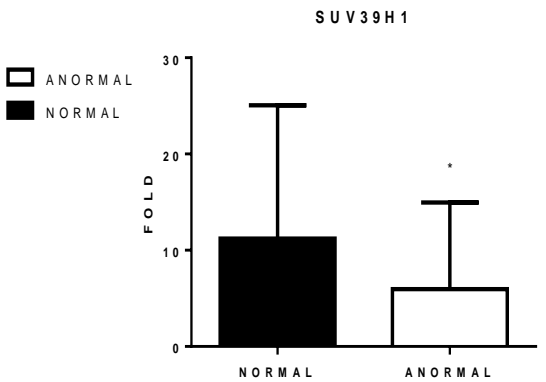

C

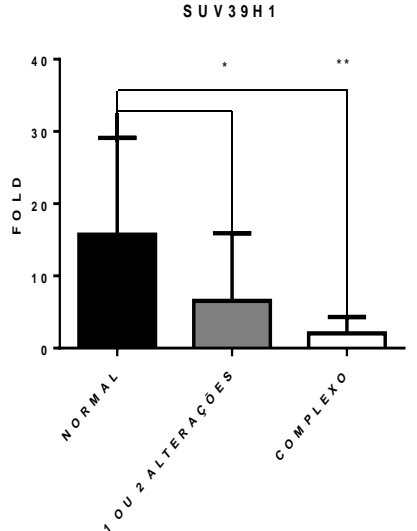

Figura 5: Associação entre a expressão de SUV39H1 e alteração cariotípica. A: Associação da expressão de SUV39H1 e número de casos com alterações cariotípicas. (Teste exato de Fisher) ( $\mathrm{p}=0.01$ ). B: Expressão de SUV39H1 em pacientes que possuem cariótipo normal e alterado. (Teste Mann Whitney) (p=0.04). C: Expressão do gene SUV39H1 em pacientes que possuem cariótipo normal, com 1 ou 2 alterações e complexo (ANOVA) $(\mathrm{p}=0.003)$.

\subsection{Expressão de SUV39H2 na leucemia linfoide crônica.}

O gene SUV39H2 se mostrou diferencialmente expresso entre pacientes com LLC e as amostras controle $(\mathrm{p}=0.04)$ (Figura 6). Devido à expressão heterogênea desse gene entre as amostras de LLC, dicotomizamos, a partir da mediana, os casos de LLC em baixa e elevada expressão de SUV39H2, para investigar a influência desse gene nos dados

laboratoriais coletados nesse estudo. É importante mencionar que algumas amostras de LLC não apresentaram expressão mensurável de SUV39H2. 


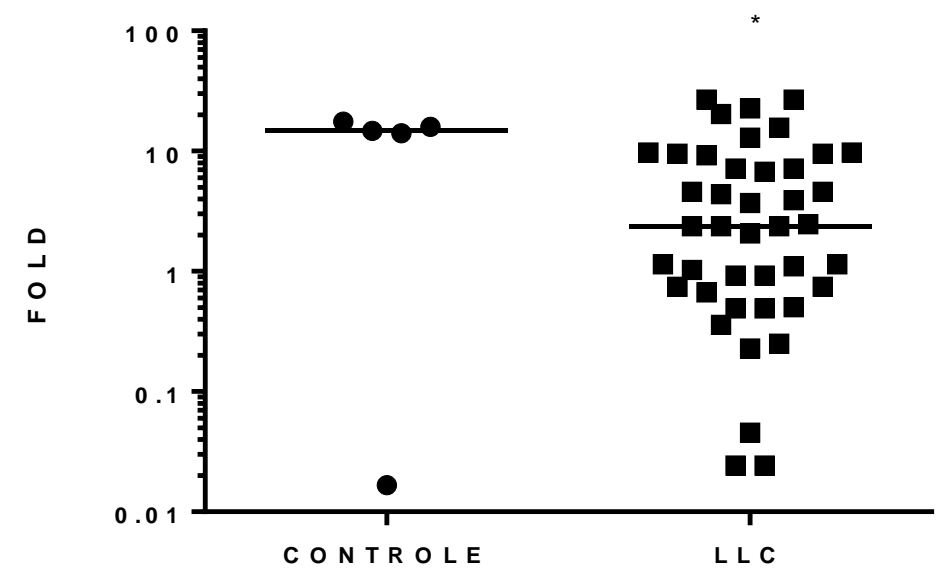

Figura 6: Expressão do gene SUV39H2 na LLC. A: A expressão do gene foi realizada em amostras de LLC e em células B de pacientes saudáveis, pela técnica de PCR. A análise estatística foi realizada pelo Teste Mann Whitney (p=0.04). 5 amostras do controle e 17 de LLC não expressaram SUV39H2.

\subsection{A expressão do gene SUV39H2 não influencia na expressão da proteína ZAP-70 e contagem de leucócitos em pacientes com LLC, mas está associada a contagem diferencial de plaquetas.}

Apesar da expressão diferencial do gene SUV39H2 (baixa e alta) não exercer influência estatisticamente significante no número de leucócitos de pacientes com LLC ( $\mathrm{p}=0.07)$, há uma tendência de maior leucometria nos casos em que a expressão de SUV39H2 está elevada. O grupo com alta expressão desse gene apresentou um quantitativo de leucócitos $20 \%$ maior que o grupo com baixa expressão. A expressão de SUV39H2 não se relacionou na expressão de ZAP-70. Observamos que a expressão elevada de SUV39H2 está associada a menor contagem de plaquetas $(p=0.01)$ em pacientes com LLC. Considerando esse achado, resolvemos estratificar os pacientes com LLC em dois grupos: contagem de plaquetas normal (150-450 mil) e baixa (inferior a 150 mil). Posteriormente, avaliamos a expressão do gene SUV39H2 para esses pacientes. 
Notamos que, de fato, os pacientes que possuem contagem baixa de plaquetas, apresentam maior expressão de SUV39H2 (p=0.02) (Figura 7).

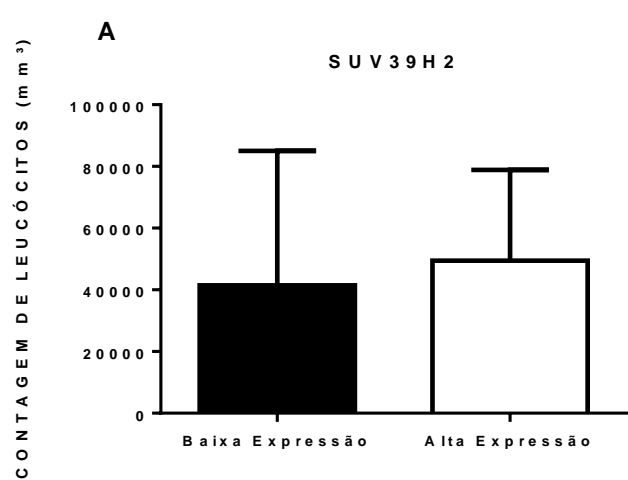

C

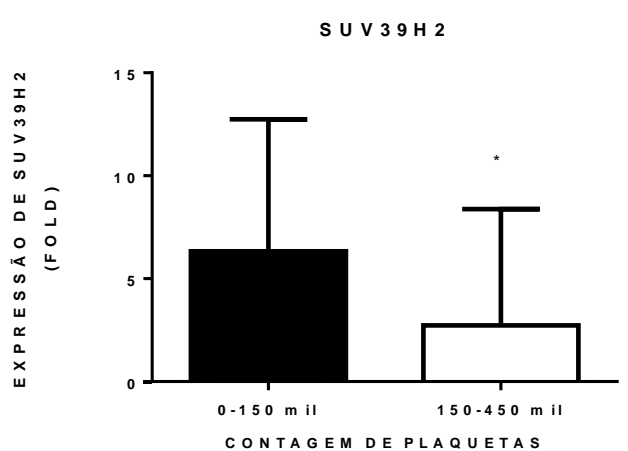

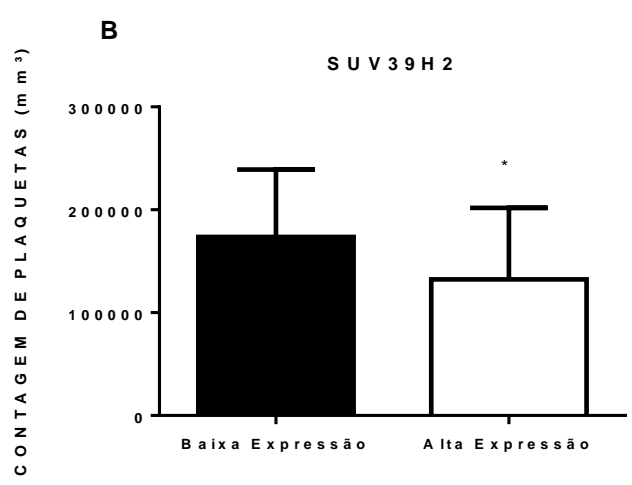

D

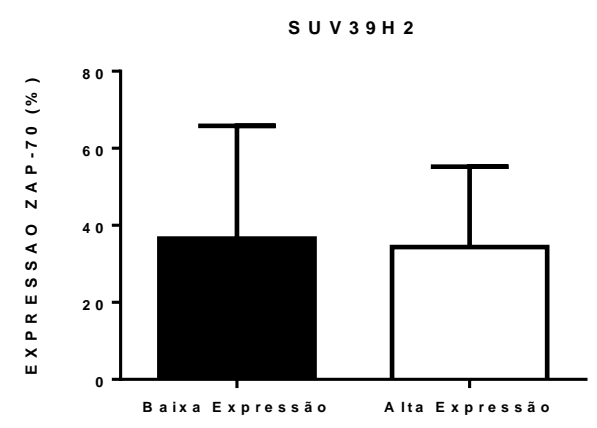

Figura 7: Associação de SUV39H2 com achados laboratoriais. A: Associação entre expressão do gene SUV39H2 e a contagem de leucócitos, B: contagem de plaquetas $(\mathrm{p}=0.01)$, C: entre grupos com contagem de plaquetas normal e alta $(\mathrm{p}=0.02)$ e D: expressão de ZAP-70 em pacientes com LLC. Teste Mann Whitney.

\subsection{A expressão elevada de SUV39H2 está associada a presença de cariótipo anormal} na LLC.

Por análise de contingência, identificamos que a alta expressão de SUV39H2 está relacionada com a frequência de cariótipos anormais ( $\mathrm{p}=0.04)$ na LLC. Considerando esse achado, estratificamos as amostras em casos que possuem cariótipo normal e aqueles que possuíam qualquer alteração cromossômica. A partir disso, avaliamos se o nível de expressão do gene SUV39H2 exercia influência no resultado citogenético. Não houve diferença significativa da expressão de SUV39H2 entre os indivíduos que apresentam 
cariótipo anormal e normal $(\mathrm{p}=0.2)$. Em seguida, avaliamos se a expressão do gene SUV39H2 exercia presença na aquisição de cariótipo complexo em pacientes com LLC. Para isso, os pacientes com LLC foram divididos em três grupos: cariótipo normal; com apenas 1 ou 2 alterações cromossômicas e cariótipo complexo. A expressão do gene SUV39H2 não demonstrou estar significativamente associada à presença de cariótipo complexo na LLC quando comparado ao grupo normal $(\mathrm{p}=0.9)$, ou quando comparada ao grupo com 1 ou 2 alterações (p=0.7) (Figura 8).
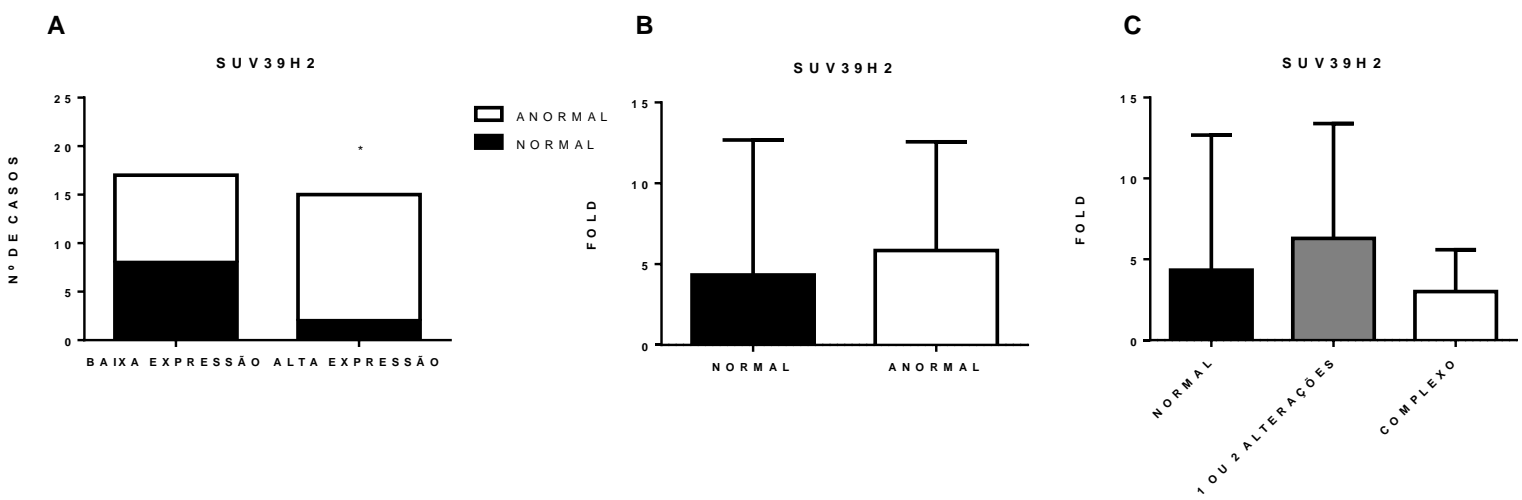

Figura 8: Associação entre a expressão de SUV39H2 e alteração cariotípica. A: associação da expressão de SUV39H2 e número de casos com alterações cariotípicas (Teste exato de Fisher) (p=0.04) B: Expressão de SUV39H2 em pacientes que possuem cariótipo normal e alterado (Teste Mann Whitney). C: Expressão do gene SUV39H2 em pacientes que possuem cariótipo normal, com 1 ou 2 alterações e complexo (ANOVA).

\subsection{Expressão de SUV4-20H1 na leucemia linfoide crônica.}

O gene SUV4-20H1 não apresenta expressão diferencial entre amostras de LLC e células B normais. ( $\mathrm{p}=0.3$ ) (Figura 9). Considerando a expressão heterogênea desse gene na doença, estratificamos essa amostragem para proceder com as investigações de associação com dados laboratoriais, conforme feito anteriormente para os outros genes. 


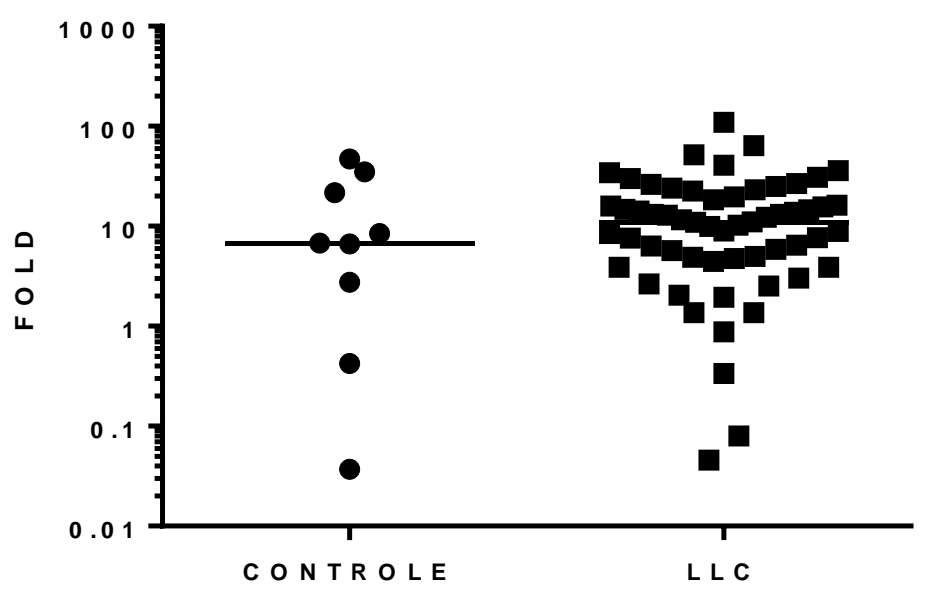

Figura 9: Expressão do gene SUV4-20H1 na LLC. A expressão do gene foi realizada em amostras de LLC e em células B de pacientes saudáveis, pela técnica de PCR. A análise estatística foi realizada pelo Teste Mann Whitney. 1 amostra do controle e 1 de LLC não expressaram SUV4-20H1.

\subsection{A expressão elevada de SUV4-20H1 está relacionada com uma baixa contagem}

total de leucócitos e não influencia na contagem de plaquetas e na expressão da proteína ZAP-70 em pacientes com $L L C$.

A baixa expressão do gene SUV4-20H1 está associada um alto quantitativo no número de leucócitos na LLC $(\mathrm{p}=0.01)$. Por outro lado, não achamos associação entre a expressão de SUV4-20H1 e o número de plaquetas na LLC $(\mathrm{p}=0.1)$. A expressão diferencial do gene SUV4-20H1 não exerceu influência na expressão da proteína ZAP$70(\mathrm{p}=0.4)($ Figura 10).

A

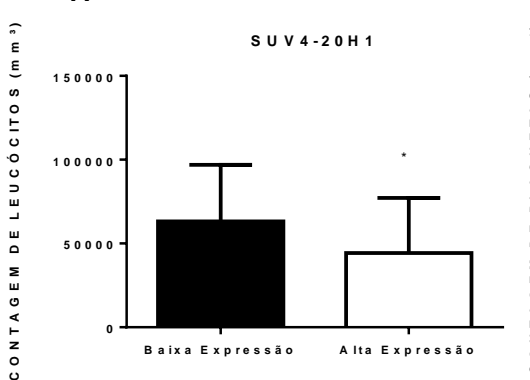

B

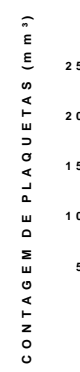

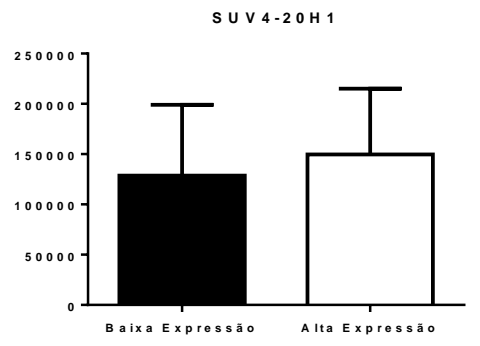

C

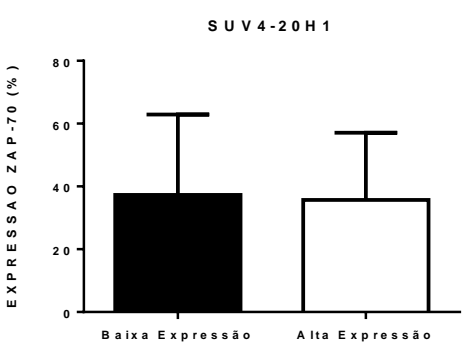

Figura 10: Associação de SUV4-20H1 com achados laboratoriais. A: Associação entre expressão do gene 
SUV4-20H1 e a contagem de leucócitos ( $\mathrm{p}=0.01)$, B: contagem de plaquetas e C: expressão de ZAP-70 em pacientes com LLC. Teste Mann Whitney.

\subsection{Nenhuma relação entre a expressão do gene SUV4-20H1 e alteração cariotípica}

foi observada em amostras de LLC.

Por análise de contingência, identificamos que a alta expressão de SUV4-20H1 não está relacionada com alteração de cariótipos na LLC. Desse modo, para aprofundar essa investigação, estratificamos a expressão do gene SUV4-20H1, conforme o padrão cariotípico normal e anormal. O resultado confirmou a análise de contingência realizada, sendo que esse gene não influencia o padrão investigado. Para investigar se SUV4-20H1 poderia exercer alguma influência em alterações mais específicas, dicotomizamos o grupo anormal em 1 ou 2 alterações e cariótipo complexo (Figura 11).

A

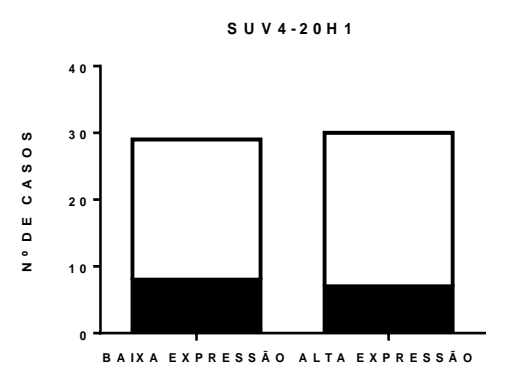

B

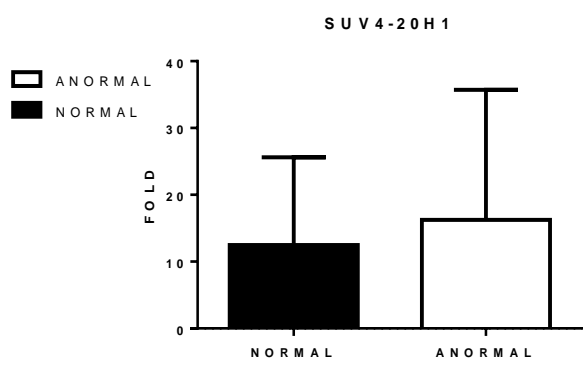

C

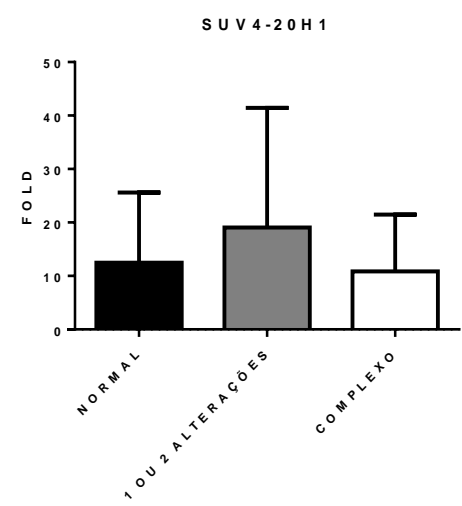

Figura 11: Associação entre a expressão de SUV4-20H1 e alteração cariotípica. A: associação da expressão de SUV4-20H1 e número de casos com alterações cariotípicas. (Teste exato de Fisher). B: Expressão de SUV4-20H1 em pacientes que possuem cariótipo normal e alterado. (Teste Mann Whitney). C: Expressão do gene SUV4-20H1 em pacientes que possuem cariótipo normal, com 1 ou 2 alterações e complexo (ANOVA).

\subsection{Expressão de SUV4-20H2 na leucemia linfoide crônica.}

Não houve diferença significativa no nível de expressão do gene SUV4-20H2 entre pacientes com LLC e as amostras controle ( $\mathrm{p}=0.2)$ (Figura 12), mas como pode ser 
visto na figura a seguir, a expressão desse gene é muito heterogênea, o que nos levou a adotar a estratificação da expressão de SUV4-20H2 para prosseguir com as investigações de associação com dados laboratoriais.

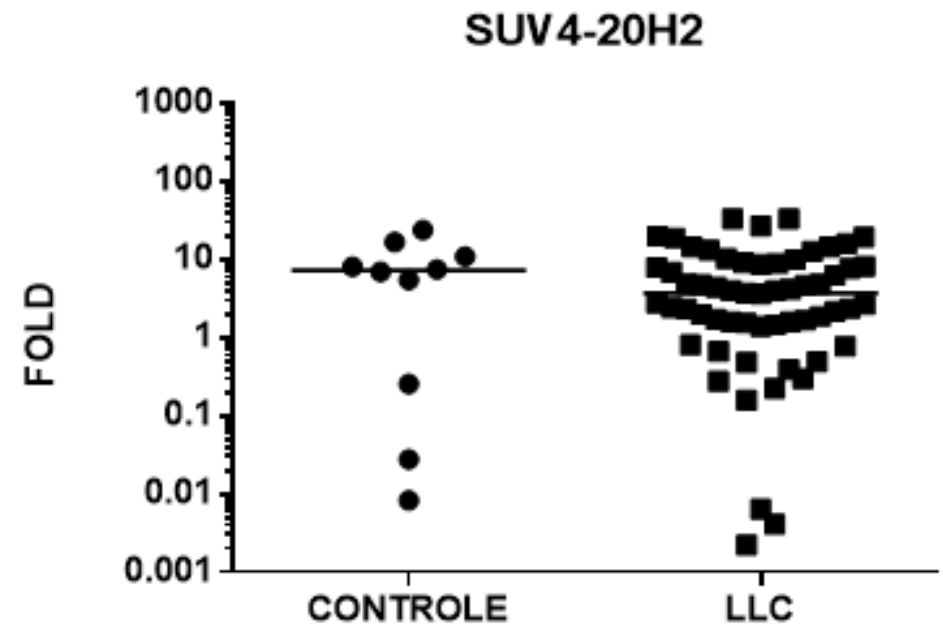

Figura 12: Expressão do gene SUV4-20H2 na LLC. A expressão do gene foi realizada em amostras de LLC e em células B de pacientes saudáveis, pela técnica de PCR. A análise estatística foi realizada pelo Teste Mann Whitney.

\subsection{A baixa expressão de SUV4-20H2 está relacionada com aumento na expressão} de ZAP-70 e não influencia na contagem de plaquetas e leucometria de pacientes com LLC.

A expressão diferencial do gene SUV4-20H2 não se correlaciona no número de leucócitos na LLC $(\mathrm{p}=0.4)$ e nem no número de plaquetas $(\mathrm{p}=0.3)$. Contudo, a baixa expressão de SUV4-20H2 está associada a maior expressão da proteína ZAP-70 em pacientes com LLC ( $\mathrm{p}=0.04)$ (Figura 13). 


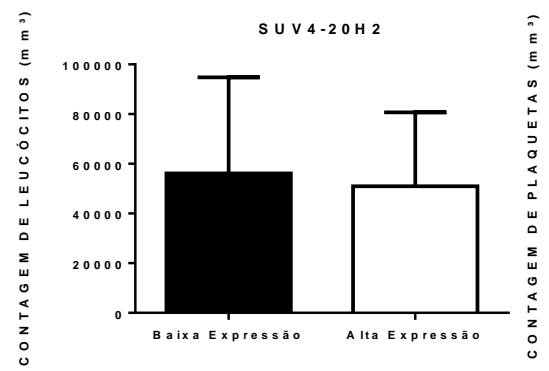

B

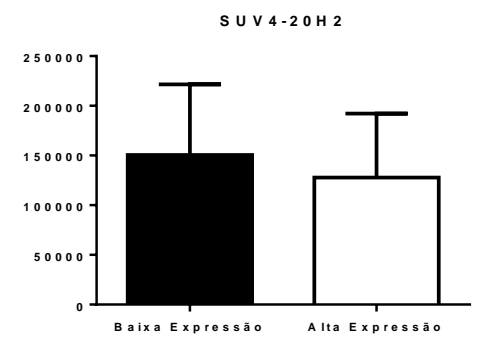

C

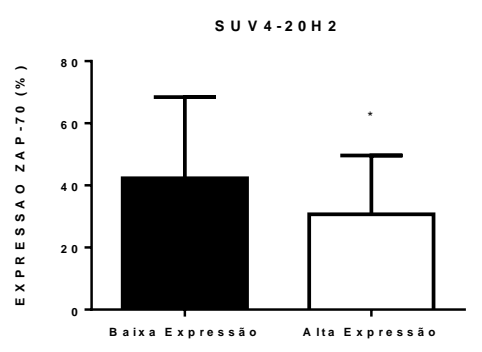

Figura 13: Associação SUV4-20H2 com achados laboratoriais. A: Associação entre expressão do gene SUV4-20H2 e a contagem de leucócitos, B: contagem de plaquetas e C: expressão de ZAP-70 (p=0.04) em pacientes com LLC. Teste Mann Whitney.

\subsection{O gene SUV4-20H2 não influencia na alteração citogenética de pacientes com}

\section{LLC}

Por análise de contingência e por estratificação do cariótipo seguindo a expressão de SUV4-20H2, identificamos que a expressão desse gene não está associada à presença de anormalidades cariotípicas na LLC (Figura 14).

A

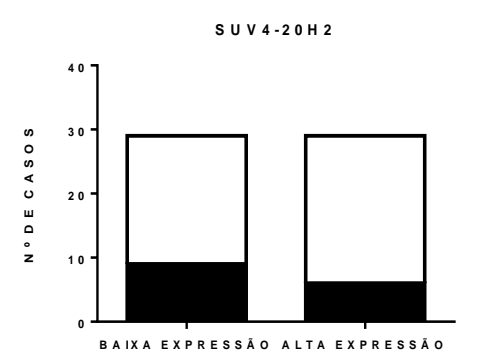

B

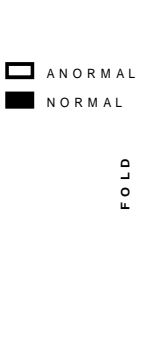

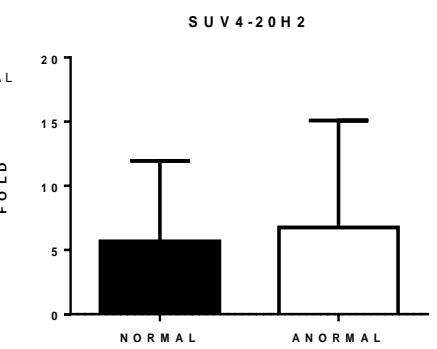

C

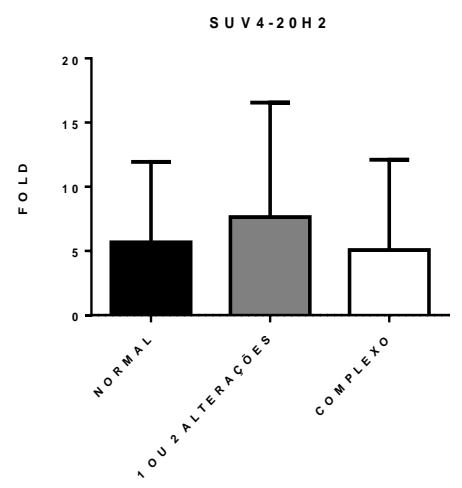

Figura 14: Associação entre a expressão de SUV4-20H2 e alteração cariotípica.A: Associação da expressão de SUV4-20H2 e número de casos com alterações cariotípicas. (Teste exato de Fisher). B: Expressão de SUV4-20H2 em pacientes que possuem cariótipo normal e alterado. (Teste Mann Whitney). C: Expressão do gene SUV4-20H2 em pacientes que possuem cariótipo normal, com 1 ou 2 alterações e complexo (ANOVA). 
4.13 O gene EHMT1 possui expressão mais elevada na LLC que em células B normais.

O gene EHMT1 é mais expresso nas amostras de pacientes com LLC que em amostras do grupo controle ( $\mathrm{p}=0.001)$ (Figura 15).

\section{E H M T 1}

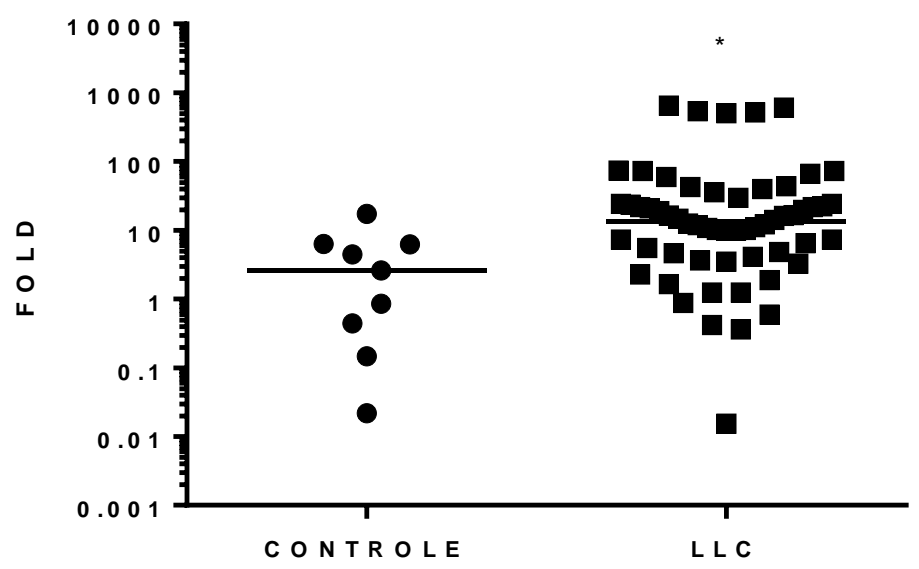

Figura 15: Expressão do gene EHMT1 na LLC.A expressão do gene foi realizada em amostras de LLC e em células B de pacientes saudáveis, pela técnica de PCR. A análise estatística foi realizada pelo Teste Mann Whitney ( $\mathrm{p=0.001).} 1$ amostra do controle e 6 de LLC não expressaram EHMT1.

4.14 A expressão do gene EHMT1 não se associa a leucometria, contagem de plaquetas e expressão da proteína ZAP-70 em pacientes com LLC.

A expressão diferencial do gene EHMT1 não se correlaciona com o número de leucócitos $(\mathrm{p}=0.4)$, de plaquetas ( $\mathrm{p}=0.1)$ e no nível de expressão da proteína ZAP-70 em pacientes com LLC ( $\mathrm{p}=0.4)$ (Figura 16). 


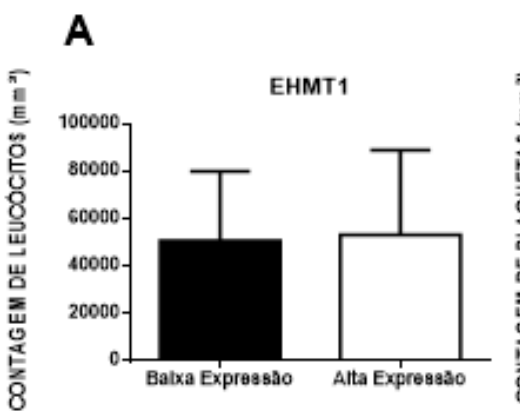

B

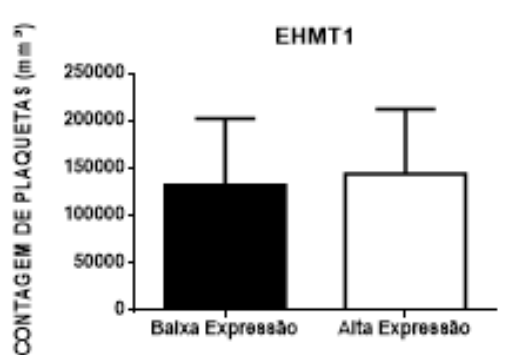

C

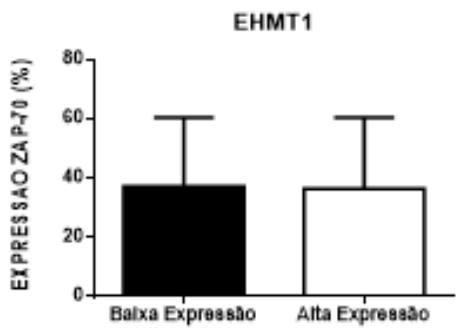

Figura 16: Associação entre EHMT1 e achados laboratoriais. A: Associação entre expressão do gene EHMT1 e a contagem de leucócitos, B: contagem de plaquetas e C: expressão de ZAP-70 em pacientes com LLC. Teste Mann Whitney.

\subsection{Nenhuma relação entre a expressão do gene EHMT1 e os cariótipos dos pacientes com LLC foi observada.}

Por análise de contingência e análise cariotípica, identificamos que a alta expressão de EHMT1 não está relacionada com diferentes tipos de cariótipos na LLC. A análise de contingência apresentou o mesmo resultado para ambos os grupos (baixa e alta expressão), uma vez que os grupos tiveram a mesma distribuição numérica entre os casos apresentados. (Figura 17). Avaliando a expressão desse gene e mudanças nos cariótipos dos pacientes, foi possível observar que não havia relação significativa

A

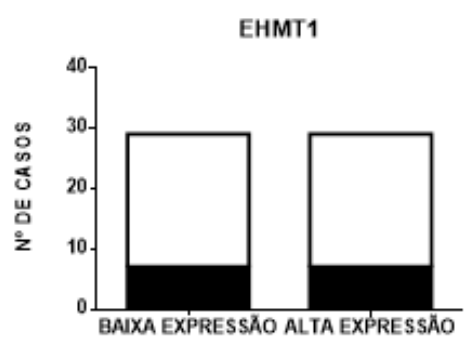

B

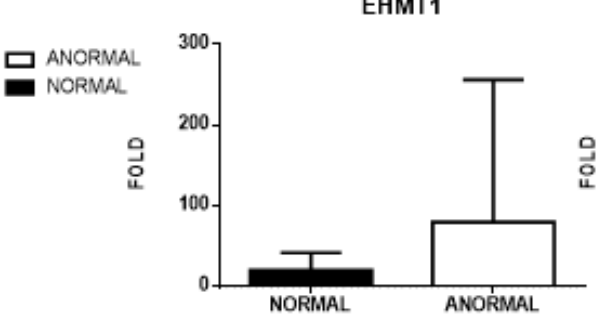

C

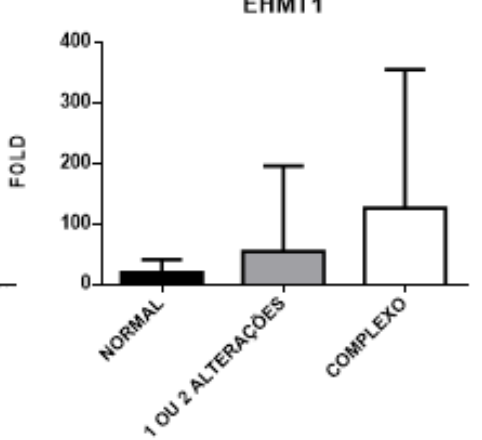

Figura 17: Associação entre a expressão de EHMT1 e alteração cariotípica.A: Associação da expressão de EHMT1 e número de casos com alterações cariotípicas. (Teste exato de Fisher). B: Expressão de EHMT1 em pacientes que possuem cariótipo normal e alterado. (Teste Mann Whitney). C: Expressão do gene EHMT1 em pacientes que possuem cariótipo normal, com 1 ou 2 alterações e complexo (ANOVA). 


\subsection{Expressão de EHMT2 na leucemia linfoide crônica.}

O gene EHMT não apresenta expressão diferencial entre amostras controles e de pacientes com LLC. Nenhuma diferença foi observada, diferentemente do resultado encontrado para o gene EHMT1 $(\mathrm{p}=0.08)$ (Figura 18).

\section{E H M T 2}

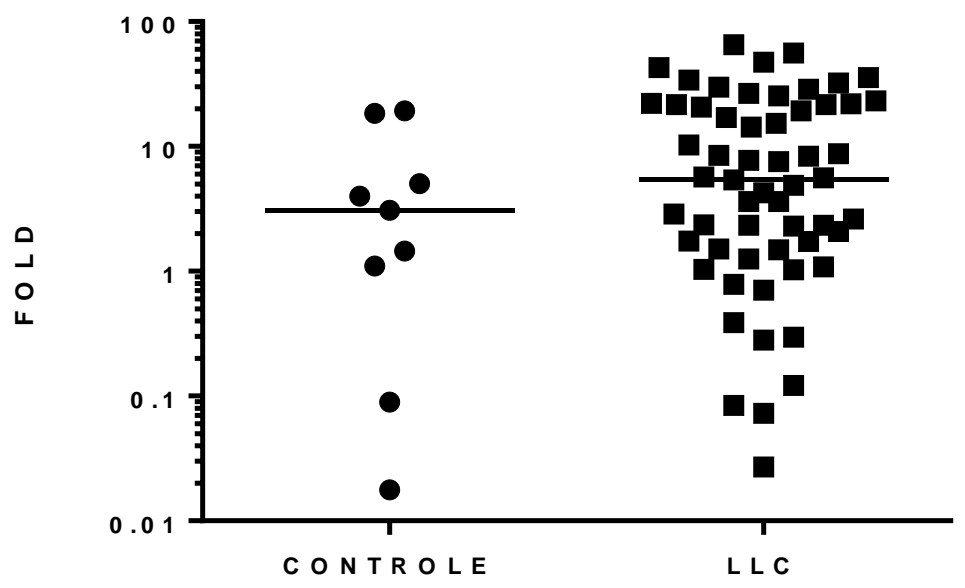

Figura 18: Expressão do gene EHMT2 na LLC.A expressão do gene foi realizada em amostras de LLC e em células B de pacientes saudáveis, pela técnica de PCR. A análise estatística foi realizada pelo Teste Mann Whitney. 1 amostra do controle e 1 de LLC não expressaram EHMT2.

\subsection{A expressão do gene EHMT2 não se associa a leucometria e expressão da} proteína ZAP-70 em pacientes com LLC. Contudo, foi observada relação com a contagem de plaquetas.

A expressão diferencial de EHMT2 na LLC não se correlaciona no número de leucócitos $(\mathrm{p}=0.09)$ nem no nível de expressão da proteína ZAP-70 ( $\mathrm{p}=0.3)$, mas a baixa expressão desse gene está associada a menor contagem de plaquetas na LLC $(\mathrm{p}=0.01)$. Considerando esse achado, resolvemos estratificar os pacientes com LLC em dois grupos: contagem de plaquetas normal (150-450 mil) e baixa (inferior a 150 mil). Posteriormente, avaliamos a expressão do gene EHMT2 para esses pacientes. É importante notar que, de 
fato, os pacientes que possuem contagem baixa de plaquetas, apresentam menor expressão de EHMT2 (p=0.03) (Figura 19).

A

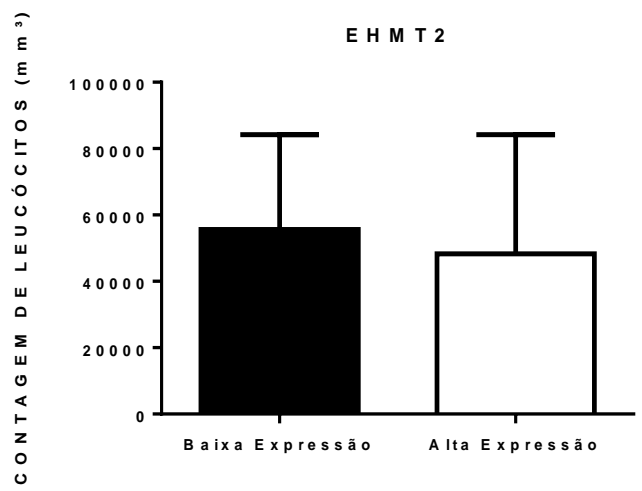

C

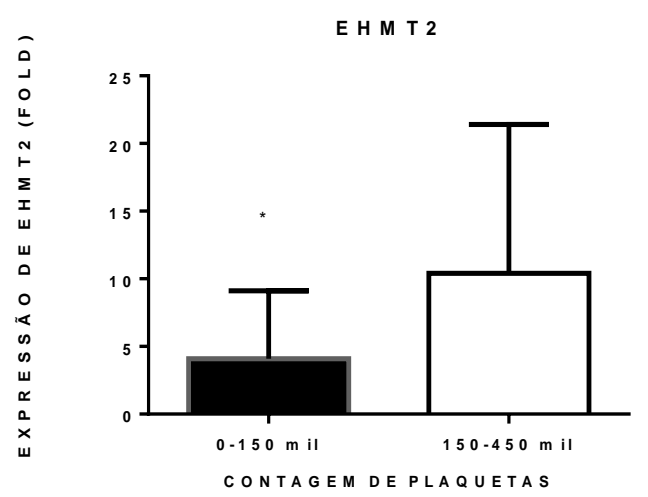

B

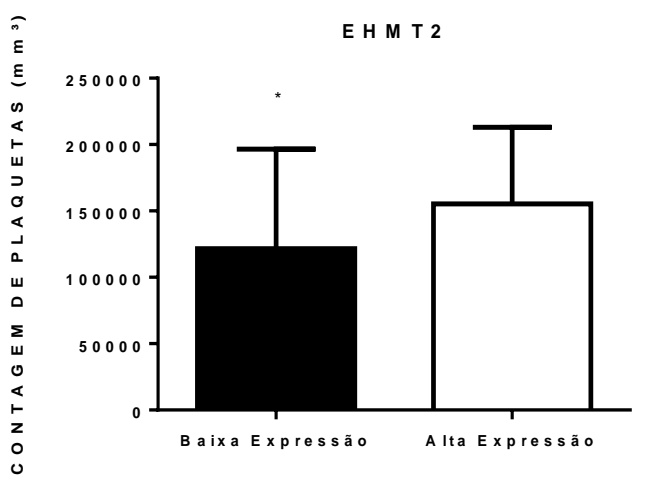

D

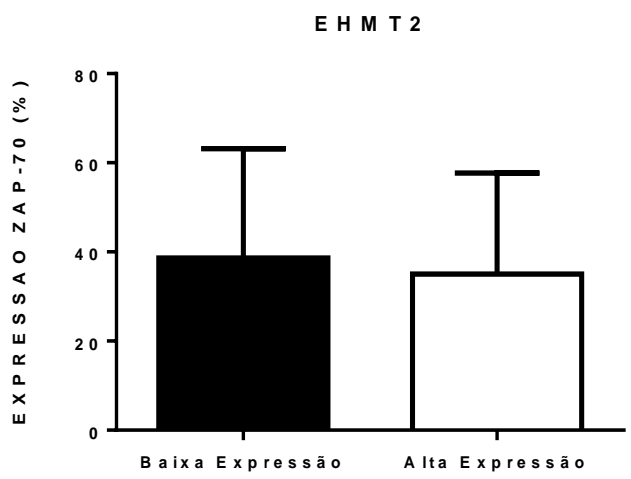

Figura 19: Associação entre EHMT2 e achados laboratoriais. A: Associação entre expressão do gene EHMT2 e a contagem de leucócitos, B: contagem de plaquetas $(\mathrm{p}=0.01), \mathrm{C}$ : entre grupos com contagem de plaquetas normal e alta $(\mathrm{p}=0.03)$ e D: expressão de ZAP-70 em pacientes com LLC. Teste Mann Whitney.

\subsection{O EHMT2 influencia o cariótipo dos pacientes com LLC}

Por análise de contingência, identificamos que a alta expressão de EHMT2 não está relacionada com alteração de cariótipos na LLC. De modo a aprofundar essa investigação, estratificamos a expressão do gene EHMT2, conforme o padrão cariotípico normal e anormal. O resultado confirmou a análise de contingência realizada, sendo que esse gene não influencia o padrão investigado. Para investigar se EHMT2 poderia exercer alguma influência em alterações mais específicas, dicotomizamos o grupo anormal em 1 ou 2 alterações e cariótipo complexo. Encontramos que quando o paciente apresentava 
cariótipo complexo, a expressão desse gene era reduzida em relação ao grupo com 1 ou 2 alterações $(\mathrm{p}=0.02)$ (Figura 20).

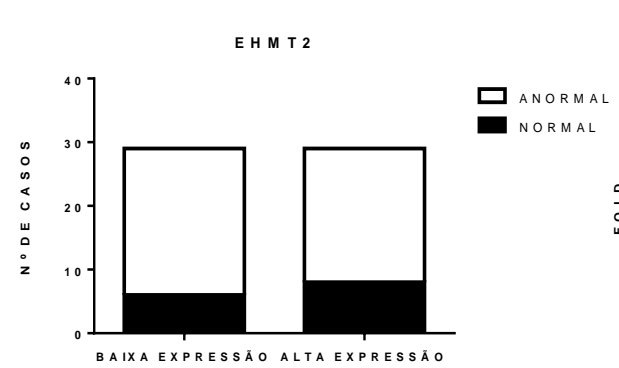

B

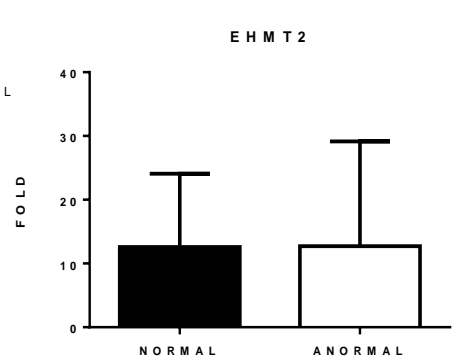

C

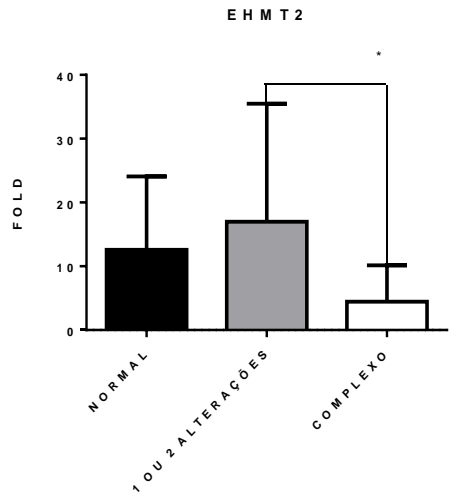

Figura 20: Associação entre a expressão de EHMT2 e alteração cariotípica. A: associação da expressão de EHMT2 e número de casos com alterações cariotípicas (Teste exato de Fisher). B: Expressão de EHMT2 em pacientes que possuem cariótipo normal e alterado. (Teste Mann Whitney). C: Expressão do gene EHMT2 em pacientes que possuem cariótipo normal, com 1 ou 2 alterações e complexo (p=0.02) (ANOVA).

\subsection{A expressão de SUV4-20H2 apresentou correlação com a expressão dos outros membros da família SUV}

Realizamos análise de correlação entre os membros da família SUV com a finalidade de verificar se existe alguma relação entre a expressão desses genes em pacientes com LLC. Notamos que o gene SUV4-20H2 apresentou correlação significativa com todos os outros genes da família. Os valores de "p" para cada correlação são apresentados na Figura 21.

A

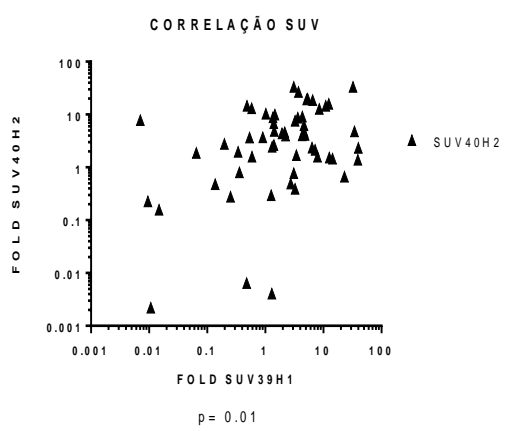

B

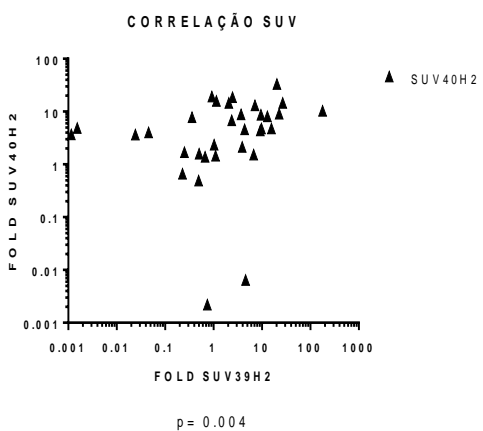

C

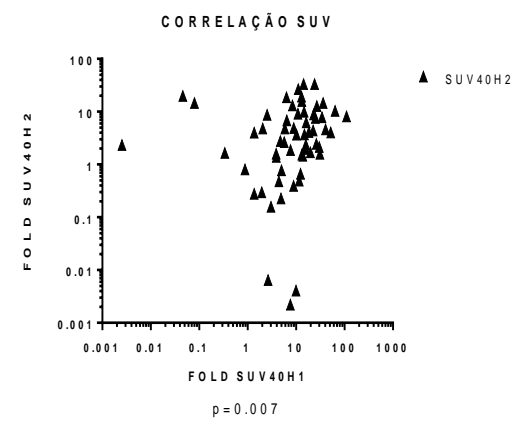


Figura 21: Correlações entre as expressões dos genes da família SUVs A) SUV39H1 e SUV4-20H2 ( $\mathrm{p}=0.01$ ) B) SUV39H2 e SUV4-20H2 ( $\mathrm{p=0.004)} \mathrm{C)} \mathrm{SUV4-20H1} \mathrm{e} \mathrm{SUV4-20H2} \mathrm{(} \mathrm{p=0.007).} \mathrm{O} \mathrm{valor} \mathrm{de} \mathrm{fold} \mathrm{foi} \mathrm{obtido}$ pela técnica de PCR.

Não foi observada correlação entre os outros membros da família. SUV39H1 X SUV39H2 ( $\mathrm{p}=0.4) ;$ SUV39H1 X SUV4-20H1 ( $\mathrm{p}=0.1) ;$ SUV39H2 X SUV4-20H1 $(\mathrm{p}=0.2)$.

\subsection{A expressão de EHMT1 apresentou correlação com a expressão de EHMT2}

Realizamos análise de correlação entre os membros da família EHMT com a finalidade de verificar se existia alguma relação entre a expressão desses genes em pacientes com LLC. Após essas análises foi notado que os genes da família EHMT estudados apresentam correlação significativa entre si.

C O R RELAÇ Ã O EH M T

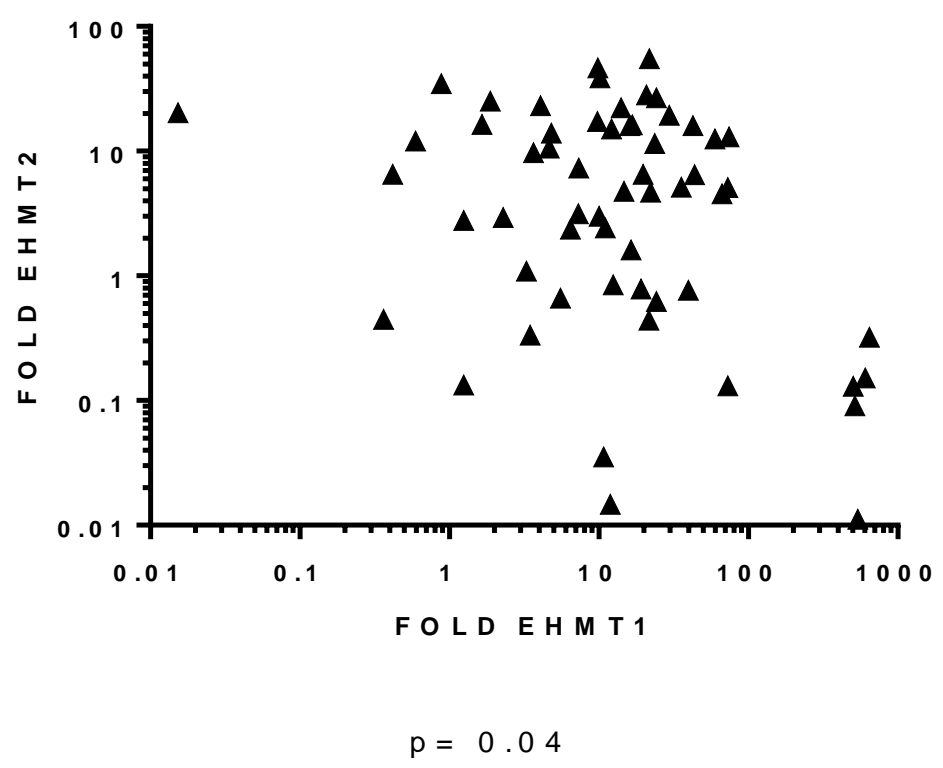

Figura 22: Correlação entre a expressão gênica do gene EHMT1 e do gene EHMT2. O valor de fold foi obtido pela técnica de PCR. 


\section{5- DISCUSSÃO}

Nesse estudo demonstramos que a expressão das famílias de metiltransferase de histonas SUV e EHMT, se correlacionam com a leucometria, contagem de plaquetas, nível de expressão de ZAP-70 e com o cariótipo em pacientes com LLC. Cada integrante dessas famílias apresentou uma relação particular com esses fatores. Embora não haja expressão diferencial de SUV39H1 em pacientes com LLC e pessoas saudáveis, a expressão desse gene na doença apresentou relação no cariótipo dos pacientes. A expressão de SUV39H2 se relacionam com a contagem de plaquetas e, além disso, a baixa expressão desse gene se associou à presença alterações citogenéticas. Os pacientes com baixa expressão de SUV40H (1 e 2) apresentaram associação com fatores de pior prognóstico na LLC, maior número de leucócitos e maior expressão de proteína ZAP-70, respectivamente. Os pacientes com LLC apresentaram maior expressão de EHMT1, entretanto, apenas EHMT2 mostrou relação com fatores prognósticos da doença, estando a menor expressão do gene relacionada à aquisição de cariótipo complexo.

A relação de SUV39H1 com o câncer tem sido investigada, sendo demonstrado que o "nocaute" desse gene leva ratos ao óbito antes mesmo do nascimento e, entre aqueles que sobrevivem, $28 \%$ desenvolvem linfoma com acúmulo de células B nos primeiros 9-15 meses de vida (PETERS A.H.F.M., et al, 2001). Também foi demonstrado na literatura que a deficiência de SUV39H1 em linhagem celular fez com que as células se multiplicassem de forma mais célere (BRAIG M., et al, 2005). Embora a deficiência de SUV39H1 esteja relacionada com a proliferação celular acentuada no linfoma, não encontramos efeito entre a expressão de gene e o acúmulo de leucócitos na LLC. 
No nosso estudo encontramos tendência de associação entre a baixa expressão de SUV39H1 e a presença de anormalidades citogenéticas, principalmente, com cariótipo complexo. Já foi demonstrado que a baixa expressão desse gene provoca instabilidade cromossômica. Além disso, SUV39H1 atua como supressor de tumor, uma vez que ratos deficientes para esse gene demonstraram instabilidade cromossômica e propensão ao desenvolvimento de linfomas das células B. Outros estudos relacionaram a deficiência de SUV39H1 com a ocorrência de instabilidade cromossômica durante a tumorigênese (TOLLEFSBOL, T. O., 2009). Foi observado também, em outro estudo, que a presença de genes "nocaute" para SUV39H1 gerou instabilidade cromossômica, aumentando a predisposição para a ocorrência de câncer (PETERS A.H.F.M., et al., 2001). Portanto, os nossos achados corroboram dados prévios e indicam que na LLC a redução na expressão de SUV39H1 pode levar a existência de alterações cariotípicas, agravamento da doença e pior prognóstico.

O gene SUV39H2 também apresenta uma relação com a ocorrência de cânceres. Foi observado que o polimorfismo desse gene está relacionado com câncer de pulmão (KYONG-AH Y, et al, 2006). No nosso trabalho identificamos que a expressão desse gene é menor nos pacientes acometidos por LLC do que em indivíduos saudáveis, o que indica que a falta ou até ausência de expressão de SUV39H2 pode atuar no surgimento/desenvolvimento dessa doença. Contudo, identificamos que quando a expressão dessa metiltransferase é elevada, os pacientes com LLC apresentam menor contagem de plaquetas. Além disso, a elevada expressão desse gene também está relacionada com o cariótipo alterado em pacientes com LLC. A relação entre plaquetas e epigenética é uma área praticamente inexplorada, poucos estudos tratam dessa relação. Apesar de dados na literatura demonstrarem que alterações no padrão de metilação podem 
influenciar na atividade funcional das plaquetas, não há dados que mostrem relação com a alteração quantitativa dessas células (FRESON, K., et al, 2012).

Leucometria acima de $5 \times 10^{9} / \mathrm{L}$ constitui um sinal de mau prognóstico na LLC (WIERDA W.G., et al, 2007). Além disso, é importante frisar que na LLC, quanto menor a contagem de plaquetas pior é o prognóstico do paciente (WINTROBE, 2003 APUD SILVA L.B., et al, 2009 BINET L., et al., 2006). No nosso estudo, os pacientes com LLC foram estratificados em grupos de contagem baixa de plaquetas e contagem normal. Essa investigação confirmou nosso achado inicial, em que a elevada expressão de SUV39H2 está associada com menor número de plaquetas na LLC. Portanto, a alta expressão de SUV39H2 se associa ao pior prognóstico na LLC, influenciando na contagem de plaquetas, cariótipo alterado e maior leucometria, haja vista que os casos em que a expressão desse gene foi elevada mostraram contagem de leucócitos aproximadamente $20 \%$ superior ao grupo que apresenta baixa expressão.

Em relação a SUV4-20H1 não existem muitas informações sobre sua relação com o câncer. É sabido que esse gene se liga na proteína do retinoblastoma $(\mathrm{Rb})$ que atua como uma proteína supressora de tumor. Foi apresentado também que a perda da trimetilação na Lys20 da histona H4 é uma característica comum de células tumorais humanas (FRAGA, et al, 2005). Além disso, as metiltransferases da família SUV4-20H, quando expressas de maneira reduzida, se mostraram importantes para a manutenção e, possível, aumento dos telômeros de células tumorais (BENETTI, et al, 2007). Ou seja, diante dessas características acredita-se que essa metiltransferase exerça um papel de supressão de tumor. No caso das leucemias, foi descrito que realmente para essa doença há uma diminuição global da trimetilação LYS20 H4, dessa forma espera-se que esse gene atue como supressor de tumor e que sua alta expressão na LLC tenha como resultado um perfil prognóstico mais favorável (FRAGA, et al, 2005). No presente estudo, demonstramos 
que a baixa expressão de SUV4-20H1 se associa à contagem elevadade leucócitos na LLC, o que constitui um fator de mau prognóstico para essa doença (WIERDA W.G., et al, 2007). O grupo que apresentou maior expressão desse gene, provavelmente possui maior taxa de trimetilação na histona 4 e com isso a supressão do tumor está sendo exercida impedindo um aumento considerável no número de leucócitos.

A relação de SUV4-20H2 e o surgimento e/ou supressão de tumores também não é bem documentada. Assim como retratado para SUV4-20H1, considera-se que SUV4$20 \mathrm{H} 2$ seja um uma metiltransferase que participa como supressora de tumor, uma vez que se liga com Rb e a metilação feita por ela é perdida em alguns tipos de câncer. Em câncer hepático foi identificada baixa expressão de SUV4-20H2 (TOLLEFSBOL, T. O., 2009). No presente trabalho foi observado que quanto menor é a expressão desse gene, maior é o nível de expressão de ZAP-70. A baixa expressão de genes da família SUV40H parece constituir um fator de mau prognóstico na LLC, corroborando com informações encontradas na literatura que associam a alta expressão desse gene como um fator de proteção contra o surgimento/desenvolvimento de cânceres (TOLLEFSBOL, T. O., 2009) e (FRAGA, et al, 2005).

Diversos estudos avaliaram a correlação de EHMT1 e EHMT2 com a ocorrência e desenvolvimento de diversos tipos de câncer. Foi demonstrado que esses genes estão altamente expressos em pacientes com câncer de fígado e que esses genes possuem papel oncogênico em silenciar genes responsáveis pela supressão de tumores (TOLLEFSBOL, T. O., 2009). Esses achados partiram de uma pesquisa que avaliou o uso da substância 5aza-20-deoxycytidine em câncer de mama, que é uma droga que diminui a metilação exercida por EHMT1 e, além disso, foi utilizado RNA de interferência para silenciar esse gene. Com essa diminuição na expressão e atividade de EHMT1 foi observado que houve 
um aumento na expressão do gene MASPIN (mammary serine protease inhibitor) que atua como um gene supressor tumoral (WOZNIAK R. J., et al, 2007).

Considerando cânceres hematológicos, foi demostrando que a inibição de EHMT1 e 2 na leucemia mieloide crônica levou a um aumento da sensibilização dessas células ao tratamento da doença e um aumento na taxa de apoptose (WEI LOH S., et al, 2014). Além disso, foi demostrado que com o uso de A-366, que age inibindo essas duas metiltransferases, em várias linhagens de leucemia in vitro, houve uma diferenciação acentuada das células neoplásicas e alterações morfológicas destes tumores, resultando na inibição do crescimento e na multiplicação do tumor (GUO J., et al, 2014).

Outros estudos demostraram que para EHMT1 foi observado que quando esse gene está altamente expresso no câncer do esôfago ocorre uma menor sobrevida dos pacientes e a expressão desse gene é um conhecido marcador de mau prognóstico (CEBRIAN, et al, 2006). O nosso estudo demonstrou que o gene EHMT1 é mais expresso nos pacientes com LLC quando comparados com as amostras controle. Portanto, é possível que esse gene esteja envolvido no desenvolvimento da doença. Com esse trabalho é possível inferir que a expressão dessa metiltransferase pode ter impacto no desenvolvimento da LLC, contudo estudos complementares são necessários para que se possa confirmar esses achados e elucidar esse mecanismo de ação.

Além de influenciar na contagem de plaquetas, a baixa expressão da metiltransferase EHMT2 se relaciona com a presença de cariótipo complexo na LLC. Os pacientes com LLC foram estratificados em grupos de contagem baixa de plaquetas e contagem normal. Essa investigação confirmou nosso achado inicial, em que a baixa expressão de EHMT2 está associada com menor número de plaquetas na LLC. Esses 
achados indicam que a perda na expressão de EHMT2 na LLC pode estar relacionada ao pior prognostico nessa doença.

Na análise de correlação da expressão gênica entre os membros da família SUV foi possível identificar que a expressão do gene SUV4-20H2 se correlaciona significativamente com a expressão dos demais membros da família. Isso pode indicar que SUV4-20H2 pode participar do mecanismo de transcrição dos outros genes da família.

Encontramos também uma correlação entre os genes EHMT1 e EHMT2, o que indicou que esses genes poderiam ter um fator de transcrição comum. De fato, por meio de análise no banco de dados GENE CARDS®, identificamos que os genes EHMT1 e EHMT2 apresentam como fator de transcrição em comum o Ativador de Fator de Transcrição 2 (ATF-2).

Esse estudo permitiu uma visão abrangente quanto a participação das metiltransferases das famílias SUV e EHMT na LLC. Foi possível observar que a expressão dessas enzimas está relacionada com diversos fatores prognósticos na LLC. Os dados apresentados nesse trabalho poderão servir de base para o desenvolvimento de novas abordagens terapêuticas que visem controlar o surgimento e progressão da LLC, com base na manipulação de mecanismos epigenéticos. 


\section{6- CONCLUSÃo}

\section{$\underline{\text { SUV39H1 }}$}

- Esse gene não possui expressão diferencial entre pacientes com LLC e pessoas saudáveis.

- A expressão de SUV39H1 se relaciona alterações no cariótipo dos pacientes com LLC.

\section{$\underline{\text { SUV39H2 }}$}

- Esse gene se mostrou menos expresso em pacientes com LLC que em pessoas saudáveis.

- Foi encontrada tendência de associação entre a expressão de SUV39H2 e a contagem de leucócitos em pacientes com LLC.

- A alta expressão de SUV39H2 em pacientes com LLC está associada a menor contagem de plaquetas.

- Por análise de contingência, identificamos que a alta expressão de SUV39H2 está relacionada com a frequência de cariótipos anormais na LLC.

\section{$\underline{\text { SUV4-20H1 }}$}

- Esse gene não possui expressão diferencial entre pacientes com LLC e pessoas saudáveis.

- A expressão elevada de SUV4-20H1 está associada a menor contagem de leucócitos em pacientes com LLC.

\section{$\underline{\text { SUV4-20H2 }}$}

- Esse gene não possui expressão diferencial entre pacientes com LLC e pessoas saudáveis. 
- A expressão elevada de SUV4-20H2 está associada a menor expressão de ZAP-70 em pacientes com LLC.

\section{$\underline{\text { EHMT1 }}$}

- Esse gene se mostrou mais expresso em pacientes com LLC do que em pessoas saudáveis.

\section{$\underline{\text { EHMT2 }}$}

Não há expressão diferencial entre pacientes com LLC e pessoas saudáveis.

- A expressão elevada de EHMT2 está associada a maior contagem de plaquetas em pacientes com LLC.

\footnotetext{
- A baixa expressão de EHMT2 está associada à ocorrência de cariótipos complexos em pacientes com LLC.
} 


\section{7- REFERÊNCIAS BIBLIOGRÁFICAS}

BENETTI R., et al., (2007). "Suv4-20h deficiency results in telomere elongation and depression of telomere recombination.” JCB Vol. 178 pp.925-936

BINET, J.L.; et al., (2006). "Perspectives on the use of new diagnostic tools in the treatment of chronic lymphocytic leukemia" Blood Vol. 107 pp.859-861

BRAIG M., et al. (2005). "Oncogene-induced senescence as an initial barrier in lymphoma development.” Nature Vol. 436 pp.660-665

CEBRIAN, et al. (2006) "Genetic variants in epigenetic genes and breast cancer risk." Carcinogenesis Vol. 27 pp.1661-1669

COCISIU, G.; et al, (2011). "The role of the monoclonal b lymphocytosis in the etiology of chronic lymphocytic leukemia." Clinical aspects Vol. 2 pp.353-356

DIGHIERO, G. \& HAMBLIN, T.J., (2008). "Chronic lymphocytic leukaemia". Lancet Vol. 371 pp.1017-1029

DOHNER, H.; et al., (2000). "Genomic aberrations and survival in chronic lymphocytic leukemia." The New England Journal of Medicine Vol. 343 pp.1910-1916

EGGER G., et al., (2004). "Review article Epigenetics in human disease and prospects for epigenetic therapy." Nature Vol. 429 pp.457-463

FRAGA, et al. (2005). "Loss of acetylation at Lys16 and trimethylation at Lys20 of histone H4 is a common hallmark of human cancer." Nature Genetics Vol. 37 pp.391400

FRESON, K., et al. (2012). "From genetics to epigenetics in platelet research." Thrombosis Research Vol. 129 pp.325-329

GHIA, P.; et al., (2007). "Chronic lymphocytic leukemia." Critical Reviews in Oncology/Hematology Vol. 64 pp.234-246

GUO J., et al. (2014) "Discovery of A-366, a novel small molecule inhibitor that uncovers an unappreciated role for G9a/GLP in the epigenetics of leukemia." The Journal of Cancer Research Cancer Vol. 74 pp.5532-5541

KONDO, Y., et al., (2008). "Gene silencing in cancer by histone H3 lysine 27 trimethylation independent of promoter DNA methylation." Nature Genetics Vol. 40 pp.741-750

KYONG-AH Y, et al. (2006). "Novel polymorphisms in the SUV39H2 histone methyltransferase and the risk of lung cancer." Carcinogenesis Vol. 27 pp.2217-2222 
LIVAK \& SCHMITTGEN, (2001). “Analysis of Relative Gene Expression Data Using RealTime Quantitative PCR and the 22DDCT Method.” Methods Vol. 25 pp.402-408

MATUTES, E, et al. (1994). "The immunophenotype of splenic lymphoma with villous lymphocytes and its relevance to the differential diagnosis with other B-cell disorders." Blood, Am Soc Hematology Vol. 83 pp.1558-1562

MAYR, C.; et al., (2006). "Chromosomal translocations are associated with poor prognosis in chronic lymphocytic leukemia.” Blood Vol. 107 pp.742-751

MULLER H. R. et al.; (2008). "Epigenética: um novo campo da genética.” RUBS Vol. 1 pp.61-69

NASCIMENTO, M., et al, (2006). "CLL: Chromosomal abnormalities (FISH) and their relation with clinical stage, CD38 and ZAP-70." Rev. Bras. Hematol. Hemoter Vol. 28 pp. $5-10$

OLIVEIRA-SANTOS W.; et al, (2016). "Residual expression of SMYD2 and SMYD3 is associated with the acquisition of complex karyotype in chronic lymphocytic leukemia." Tumor Biology Vol. 37 pp.9473-9481

PASCHON, V., et al., (2014). "Formação da memória está associada com mecanismos epigenéticos que são passados de geração para geração (cérebro Lamarkiano).” Nanocell News Vol. 1 pp.1-4

PETERS A.H.F.M., et al. (2001). "Loss of the SUV39H histone methyltransferases impairs mammalian heterochromatin and genome stability." Cell Vol. 107 pp.323-337

PFAFFL M. W., (2001). " A new mathematical model for relative quantification in realtime RT-PCR.” Nucleic Acids Research Vol. 29 pp.9-14

RABELLO, D.A.; et al., (2015). "Overexpression of EZH2 associates with a poor prognosis in chronic lymphocytic leukemia". Blood Cells, Molecules and Diseases Vol. 54 pp.97-102

RAI, K.R.; et al., (1975). “Clinical staging of chronic lymphocytic leukemia”. Blood Vol. 46 pp. $219-234$

REECE J., et al., (2002). Biology. San Francisco: Benjamin Cummings. ISBN 0-80536624-5. Disponível em: https://probiokelinton.wordpress.com/2010/04/28/o-nucleo-dacelula-parte-2/ Acesso: 10/02/2016.

SAKAMOTO, L.H.T.; et al., (2014). "SMYD2 is highly expressed in pediatric acute lymphoblastic leukemia and constitutes a bad prognostic factor". Leukemia Research Vol. 38 pp.496-502

SILVA L.B., et al. (2009). “Avaliação do perfil hematológico de pacientes com leucemia linfocítica crônica (LLC-B) em um hemocentro estadual.” Rev. Bras. Hematol. Hemoter Vol. 31 pp.228-234 
TOLLEFSBOL, T. O.; (2009). “Cancer epigenetics.” Florida, CRC Press pp.1-472

VASCONCELOS, Y.; (2005). "Marcadores de prognóstico na leucemia linfocítica crônica.” Rev. Bras. Hematol. Hemoter Vol. 27 pp.253-256

WARD LS., (2002). "Entendendo o processo molecular da tumorigênese / Understanding the molecular process of tumorigenesis.” Arq. Bras. Endocrinol. Metab Vol. 46 pp.351360

WEI LOH S., et al. (2014). "Inhibition of Euchromatic Histone Methyltransferase 1 and 2 Sensitizes Chronic Myeloid Leukemia Cells to Interferon Treatment." PLOS One Vol.9 pp.7-20

WIERDA, W.G.; et al., (2007). "Prognostic nomogram and index for overall survival in previously untreated patients with chronic lymphocytic leukemia". Blood Vol. 109 pp.4679-4685

WOZNIAK R. J., et al. (2007). "5-Aza-20-deoxycytidine-mediated reductions in G9A histone methyltransferase and histone $\mathrm{H} 3 \mathrm{~K}$ 9 di-methylation levels are linked to tumor suppressor gene reactivation." Oncogene Vol. 26 pp.77-90

ZENT C. S.; et al., (2008). "The prognostic significance of cytopenia in chronic lymphocytic leukaemia/small lymphocytic lymphoma" British Journal of Haematology Vol. 141 pp.615-621 